\title{
A New Era of Pulmonary Delivery of Nano-antimicrobial Therapeutics to Treat Chronic Pulmonary Infections
}

\author{
Zahra Merchant $^{\mathrm{a}}$, Graham Buckton ${ }^{\mathrm{a}}$, Kevin M.G. Taylor ${ }^{\mathrm{a}}$, Paul Stapleton ${ }^{\mathrm{b}}$ Imran Y. Saleem $^{\mathrm{c}}$, \\ M.Gulrez Zariwala ${ }^{\mathrm{d}}$ and Satyanarayana Somavarapu*a
}

${ }^{a}$ Department of Pharmaceutics, School of Pharmacy, University College London, London, United Kingdom

${ }^{b}$ Department of Pharmaceutical \& Biological Chemistry, School of Pharmacy, University College London, London, United Kingdom

c School of Pharmacy \& Biomolecular Sciences, Liverpool John Moores University, Liverpool, United Kingdom

${ }^{d}$ Faculty of Science \& Technology, University of Westminster, London, United Kingdom

\begin{abstract}
Pulmonary infections may be fatal especially in immunocompromised patients and patients with underlying pulmonary dysfunction, such as those with cystic fibrosis, chronic obstructive pulmonary disorder, etc. According to the WHO, lower respiratory tract infections ranked first amongst the leading causes of death in 2012, and tuberculosis was included in the top 10 causes of death in low income countries, placing a considerable strain on their economies and healthcare systems. Eradication of lower respiratory infections is arduous, leading to high healthcare costs and requiring higher doses of antibiotics to reach optimal concentrations at the site of pulmonary infection for protracted periods. Hence direct inhalation to the respiratory epithelium has been investigated extensively in the past decade, and seems to be an attractive approach to eradicate and hence overcome this widespread problem. Moreover, engineering inhalation formulations wherein the antibiotics are encapsulated within nanoscale carriers could serve to overcome many of the limitations faced by conventional antibiotics, like difficulty in treating intracellular pathogens such as mycobacteria spp. and salmonella spp., biofilm-associated pathogens like Pseudomonas aeruginosa and Staphylococcus aureus, passage through the sputum associated with disorders like cystic fibrosis and chronic obstructive pulmonary disorder, systemic side effects following oral/parenteral delivery and inadequate concentrations of antibiotic at the site of infection leading to resistance. Encapsulation of antibiotics in nanocarriers may help in providing a protective environment to combat antibiotic degradation, confer controlled-release properties, hence reducing dosing frequency, and may increase uptake via specific and non-specific targeting modalities. Hence nanotechnology combined with direct administration to the airways using commercially available delivery devices, is a highly attractive formulation strategy to eradicate microorganisms from the lower respiratory tract, which might otherwise present opportunities for multi-drug resistance.
\end{abstract}

Keywords: bacterial resistance, biofilm, cystic fibrosis, infection, nanoparticle, liposome, pulmonary, tuberculosis.

\section{BACKGROUND}

Inhalation is one of the oldest forms of medicament delivery dating back to the ancient Egyptian civilization where inhalation of vapours of black henbane were employed to help breathless patients breathe [1]. Currently, this complex route is used primarily for local treatment of respiratory diseases, such as cystic fibrosis, chronic obstructive pulmonary disease (COPD), bronchiectasis, asthma, pneumonia, aspergillosis and tuberculosis. Small molecules such as glucocorticoids e.g. budesonide, fluticasone, beclometasone; $\beta_{2}$-adrenoceptor agonists e.g. salbutamol (albuterol), terbutaline, salmeterol, anti-

*Address correspondence to Satyanarayana Somavarapu, Department of Pharmaceutics, School of Pharmacy, University College London, 29-39 Brunswick Square, London WC1N 1AX; United Kingdom; Tel.: +44 2077535987; s.somavarapu@ucl.ac.uk muscarinic bronchodilators e.g. ipratropium, tiotropium and antimicrobials e.g. tobramycin, aztreonam, colistin, pentamidine have been, and are being successfully administered to the lungs for treatment of respiratory diseases. In this way, the drug directly reaches the desired site of action, leading to the possibility of dose reduction as compared to oral and parenteral routes, reducing medicament costs and also ensuring a higher concentration of drug is retained at the target site [2,3]. This reduces the possible side effects due to decreased systemic exposure and helps in achievement of faster onset of action [3]. Numerous studies have demonstrated that antimicrobials, such as amikacin, tobramycin, rifampicin and amphotericin B used for treatment of lower respiratory tract infections caused by organisms like Pseudomonas aeruginosa, Candida albicans and Mycobacterium tuberculosis have 
serious adverse effects, including ototoxicity and nephrotoxicity, when administered orally or IV, which are ameliorated by a direct pulmonary delivery [4-8]. Due to the relatively low metabolic activity in the lung, pulmonary delivery is attractive for delivery of drugs which are sensitive to gastric $\mathrm{pH}$, enzymes and metabolizing enzymes, particularly those associated with metabolism within the liver [9]. It is also useful for drugs belonging to Class IV of the Biopharmaceutics Classification System, such as amphotericin B, which has low water solubility and low membrane permeability, resulting in limited oral absorption and hence is administered routinely by the invasive IV route [10-12].

Effective pulmonary drug delivery requires sophisticated aerosol formulation approaches and complex delivery devices. Moreover, pulmonary delivery is a challenge due to the complex anatomy and physiology of the airways, restricting access and promoting clearance of inhaled materials [3].

\section{PRE-REQUISITES FOR INHALATION: FACTORS AFFECTING PULMONARY DRUG DEPOSITION}

The therapeutic effect of an inhaled medicament depends largely on its deposition pattern and distribution in the lungs; hence, understanding the concepts and mechanisms of these processes is of fundamental importance to inhalation therapy. Deposition is a process by which particles stick or adhere to the surface [13].

From a formulation viewpoint, the deposition profile is largely dependent on the aerosol particle characteristics, namely: aerodynamic size, particle size distribution, shape, density, electric charge, hygroscopicity and stability. Other factors include lung morphology, clearance mechanisms (mucociliary and alveolar macrophages), type and severity of lung disease, airflow obstruction and patient factors, such as inhalation pattern, flow rate, breath-holding time, correct use of devices, etc.[14-15].

Aerosol particle deposition in the airways is governed by three main mechanisms namely: Inertial impaction, gravitational sedimentation and Brownian diffusion [15].

Inertial impaction: Large particles with high momentum (i.e. product of mass and velocity) do not follow the lung structure with the flowing air stream and are deflected by the airway branching due to inertia and hence convective fluid motion leading to deposition on the airway wall $[13,15,16]$. This occurs mainly at the airway bifurcations of large conducting zones of airway and nose, mouth, pharynx, larynx and bronchial region. This is a velocity-dependent mechanism is the main method for deposition of particles greater than $5 \mu \mathrm{m}$ [17].

Gravitational sedimentation: This results from the gravitational force acting on particles with sufficient mass. Deposition due to gravity increases with increasing particle size, density and with longer residence time, acting when the particle velocity is low resulting in loss of balance between the gravitational force and the drag force of air leading to subsequent deposition on the lower airway surface.
Gravitation sedimentation is an important mechanism of deposition for particles in the range 0.5-3 $\mu \mathrm{m}$ in small conducting airways, like bronchioles and alveoli where the air flow rate is low $[13,15,16]$.

Diffusion: This mechanism of deposition predominates for particles $<0.5 \mu \mathrm{m}$ and is governed by random Brownian motion. Particles are displaced by random motions of air molecules, move along the airway streamlines, and deposit on contact with the cells by sequential bombardments. Deposition by diffusion is directly proportional to particle size and occurs in the alveoli and smaller respiratory bronchioles, where bulk airflow rate is low or absent [13, $15]$.

Aerosol characteristics:

Aerodynamic diameter is the most important physical property of an aerosol that governs the proportion of the dose deposited in the airways and can be described as:

$$
d_{\mathrm{ae}}=d_{g}\left(\rho_{\mathrm{e}} / \rho_{\mathrm{s}} \lambda\right)^{1 / 2}
$$

where, $d_{g}$ is the particle geometric diameter, $\rho_{\mathrm{e}}$ and $\rho_{\mathrm{s}}$ are the effective particle and unit $\left(1 \mathrm{~g} / \mathrm{cm}^{3}\right)$ density respectively and $\lambda$ is the dynamic shape factor of the particle, i.e. the ratio of particle drag force to that of a sphere of equivalent volume and is 1 for a perfect sphere. Aerodynamic diameter explains the movement of aerosol particles in an air flow not only with respect to their geometric diameter but also taking into consideration their shape and density [18].

Surface roughness of a particle impacts the aerosolization efficiency of a dry powder inhalation as it determines the interaction forces between the drug particles and between the drug and carrier particles (if present) in a formulation. An appropriate balance between the interaction forces (during mixing/filling) and separation forces (during inhalation) of these particles is essential to ensure efficient delivery of the medicament to the peripheral lung, when delivered as dry powder inhalations [19-21]. Studies have demonstrated that an increase in surface roughness of lactose carrier particles and sieved sorbitol particles proportionately improves the drug carrying capacity of the carrier; however the drug particles are held tightly to the carrier particles and hence the emitted dose from the inhaler device decreases [19-21].

Particle shape plays an important role in the aerodynamics of dry powders. Studies have shown that the elongation ratio and shape factor of a particle dictates its trajectory in the respiratory tract. Rod-shaped particles of carrier lactose showed an increase in fine particle fraction compared to approximately spherical particles, due to a spatial hindering effect $[20,22]$. Another study performed on rod-shaped cromoglicic acid showed an increased fine particle fraction due to their shape being analogous to that of asbestos fibres which have a higher susceptibility for pulmonary deposition $[23,24]$. The study of the relationship between shape and surface properties is important as it can affect the aerodynamics of dry powders. With higher elongation ratios, the contact area between the particles is greater, leading to an increased cohesiveness between the particles which may ultimately affect the aerodynamic performance of the particles. 
Other than size, shape and surface roughness, deposition is also governed by various other formulation parameters, such as hygroscopicity, polymorphic form, inter-particular forces and surface charge.

\section{PULMONARY DRUG DELIVERY DEVICES}

Aerosols are an effective way to deliver medications to the pulmonary site. These are two-phased, stable dispersions or suspensions of solid or liquid droplets in a gaseous phase usually air, and can be generated by a passive breath-driven or an active single or multiple dose inhaler [25]. Therapeutic aerosols can be delivered using three broad types of devices, namely: nebulizers, pressurized metered dose inhalers (pMDIs) and dry powder inhalers (DPI), though other delivery means have been described. The advantages and disadvantages of the different inhaler devices are outlined in Table 1.

\subsection{Nebulizers}

These were the first devices to be used and they are still employed for pulmonary drug delivery by the pediatric and geriatric populations for delivering drugs such as salbutamol for pediatric asthma, sodium cromoglicate inflammation, tobramycin for infections associated with cystic fibrosis and COPD, corticosteroids and bronchodilators for severe COPD, etc. Nebulizers needs minimum patient skills or inhalation/actuation co-ordination [26]. Nebulizers deliver drug in droplets generated from solutions or suspensions. They have an advantage of delivering large doses during tidal breathing. Nebulizers can be classified as:

Pneumatic or jet nebulizers: These operate on the Bernoulli principle by which high velocity compressed air passes through narrow orifice creating an area of low pressure at the outlet, causing the drug solution to be drawn up from the reservoir, forming a liquid film which breaks down into liquid droplets due to surface tension. Large droplets are retained in the device and a fine mist emitted for inhalation via a mouthpiece or facemask $[14,27]$.

Ultrasonic nebulizers: These contain a piezoelectric crystal which vibrates at a frequency of $1-3 \mathrm{MHz}$ producing waves which are transmitted to the surface of a drug solution leading to formation of standing waves, forming a fountain of fine mist. Small droplets, having a size inversely proportional to the value of crystal vibrational frequency, are produced in the mist [14, 27, 28].

Vibrating-mesh nebulizers: These contain a piezo-element which vibrates a perforated membrane in resonant bending mode. The cross-section of the perforations is larger at the reservoir side and narrower at the droplet emergence side. The size of aerosol droplets produced can be modulated by changing the number of perforations and their sizes [29].

Electrohydrodynamic atomizers (EHDA): Also referred to as electrospraying, these produce particles suitable for deep lung delivery by a low-shear technique wherein application of electrical forces in a controlled manner can be useful in production of monodispersed droplets of size in the nanometric to micrometric range depending on the frequency applied during particle production [30]. Studies performed by Chattopadhyay et.al [31] compared the atomization of DPPC:DPPG:Chol liposomes using jet atomization and electrospraying highlighted that on atomization of lower concentration of liposomal suspensions $\left(0.1 \mathrm{mg} \mathrm{ml}^{-1}\right)$ using jet atomizers only $15 \%$ of droplets contained liposomes whereas the rest was constituted of only buffer salt particles. However, when atomizing using electrospraying higher droplet lipid mass concentrations could be obtained [31].

\subsection{Pressurized metered-dose inhalers: pMDIs}

These multi-dose devices have an aluminium canister equipped with a metering valve which contains drug dissolved or suspended in liquid propellant(s) along with other excipients, such as surfactants, e.g. SPAN 85, oleic acid and soya lecithin and co-solvents, usually ethanol. Actuation of the valve leads to emission of the aerosol as a metered dose of drug dissolved or dispersed in propellant, usually a hydrofluoroalkane [14, 27, 28, 32].

\subsection{Dry Powder Inhalers: DPIs}

Subsequent to the development of pMDIs, dry powder inhalers (DPIs) were designed, and these received added interest in recent years as ozone-depleting chlorofluorocarbon (CFC)-based pMDIs have been phased out for environmental reasons. DPIs have no propellant and in some respects are more user friendly devices [33].

DPIs exist in many designs which need for their operation a degree of manual dexterity, although simpler DPIs are being researched [34]. DPIs dispense a metered quantity of powder in an air stream drawn through an inlet system by the patient's inspiration, directing air through the loose powder aggregates and forming a drug aerosol cloud. Hence, these are passive breath-actuated devices $[28,35]$. They are robust, portable and convenient in terms of formulation, processing and stability as they are a one-phase solid system. They do not require to be sterile and avoid the formulation issues of nebulizers and pMDIs, particularly for suspension formulations, such as sedimentation, flocculation and foaming which may impact performance [36].

DPIs are receiving increasing interest due to drawbacks of the use of propellants and the requirement of inhalationactuation synchronization when using pMDIs. However, this class of devices is subject to strict regulatory manufacturing and pharmaceutical standards so that they are reproducible and reliable with respect to delivered dose uniformity [37]. This requires that a number of characteristics of the DPI highlighted below should be satisfied in order to achieve patience adherence, device reproducibility/reliability and clinical efficacy.

The characteristics of an ideal DPI can be divided on the basis of:

$>$ Patient acceptance [37-39]

- Simple operation

- Portable and easy to carry

- Multiple dosage reservoir

- Cost effective and/or reusable

- Dose counter, dose-ready indicator and an audiovisual indicator of doses remaining 
- Patient feedback mechanism to indicate successful dosage administration

Device reliability and reproducibility with respect to dosing [37-41]

- Consistent and homogeneous dose delivery of medicament throughout the life of inhaler, at least comparable to a pMDI

- Accurate and uniform dose delivery of medicament over a wide range of inspiratory flow rates with minimal variation with respect to age, gender and disease state

- Optimum and reproducible control on respirable fractions with high fraction of particles in respirable range for deep lung delivery

- Low oropharyngeal deposition with high bronchial deposition

Efficient device [37-41]

- Good protection from environmental moisture to prevent change in powder aerosol characteristics

- In-process quality control

- Minimal adhesion between the drug and inhalation device

- Device suitable for a wide range of drugs and doses

- Environmentally accepted device

No DPI can fulfil all the requirements of an ideal inhaler; however, continuous research is being conducted to improve their performance to achieve optimal fine particle dosage of medicament, with improved patient acceptability. Patient education is of utmost importance with regards to use and storage of their DPI preparations.
Table 1: Advantages and disadvantages of different inhaler devices

\begin{tabular}{|c|c|c|c|}
\hline 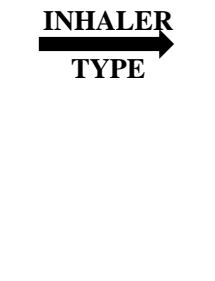 & $\begin{array}{c}\text { NEBULIZER } \\
\text { (JET, } \\
\text { ULTRASONI } \\
\text { C, } \\
\text { VIBRATING } \\
\text { MESH) }\end{array}$ & $\begin{array}{c}\text { PRESSURIZ } \\
\text { ED } \\
\text { METERED- } \\
\text { DOSE } \\
\text { INHALER } \\
\text { (pMDI) }\end{array}$ & $\begin{array}{c}\text { DRY } \\
\text { POWDER } \\
\text { INHALER } \\
\text { (DPI) }\end{array}$ \\
\hline ADVANTAGES & $\begin{array}{l}\text { Does not } \\
\text { require } \\
\text { inhalation } \\
\text { actuation } \\
\text { synchronization } \\
\text { No propellant } \\
\text { High doses can } \\
\text { be delivered } \\
\text { Optimal for } \\
\text { pediatric, } \\
\text { geriatric and } \\
\text { diseased } \\
\text { patients who } \\
\text { cannot use other } \\
\text { devices } \\
\text { Present } \\
\text { generation of } \\
\text { vibrating-mesh } \\
\text { nebulizers can } \\
\text { be battery } \\
\text { operated and } \\
\text { hence portable } \\
\text { (e.g: Aerogen } \\
\text { Vibronic }\end{array}$ & $\begin{array}{l}\text { Portable and } \\
\text { compact } \\
\text { No } \\
\text { preparation } \\
\text { required } \\
\text { No } \\
\text { contamination } \\
\text { risk } \\
\text { Multidose } \\
\text { (approx. } 200 \\
\text { doses) } \\
\text { High } \\
\text { reproducibilit } \\
\text { y between } \\
\text { doses } \\
\text { Sealed } \\
\text { environment } \\
\text { prevents drug } \\
\text { degradation } \\
\text { Cost-effective }\end{array}$ & $\begin{array}{l}\text { Portable and } \\
\text { compact } \\
\text { Does not } \\
\text { require } \\
\text { inhalation } \\
\text { actuation } \\
\text { synchronization } \\
\text { No propellant } \\
\text { Ease in use } \\
\text { Breath actuated } \\
\text { No need for } \\
\text { spacers }\end{array}$ \\
\hline $\begin{array}{c}\text { DISADVANTA } \\
\text { GES }\end{array}$ & $\begin{array}{l}\text { Expensive, } \\
\text { wasteful } \\
\text { Contamination } \\
\text { risk } \\
\text { Time } \\
\text { consuming } \\
\text { Different } \\
\text { models and } \\
\text { operating } \\
\text { conditions lead } \\
\text { to high } \\
\text { performance } \\
\text { variability } \\
\text { Drug } \\
\text { formulation } \\
\text { preparation may } \\
\text { be necessary } \\
\text { Nebulizer } \\
\text { performance } \\
\text { may decline } \\
\text { over time }\end{array}$ & $\begin{array}{l}\text { Requires } \\
\text { inhalation- } \\
\text { actuation } \\
\text { synchronizati } \\
\text { on } \\
\text { High } \\
\text { oropharyngea } \\
1 \text { deposition } \\
\text { observed } \\
\text { Maximum } \\
\text { dosage that } \\
\text { can be } \\
\text { administered } \\
\text { is } \\
\text { approximatel } \\
\text { y } 5 \text { mg } \\
\text { Young } \\
\text { children } \\
\text { require } \\
\text { valved- } \\
\text { holding } \\
\text { chamber } \\
\text { (spacer) } \\
\text { Propellant- } \\
\text { based }\end{array}$ & $\begin{array}{l}\text { Respirable dose } \\
\text { dependent on } \\
\text { inspiratory flow } \\
\text { rate, tidal } \\
\text { volume, } \\
\text { breathes/cycle } \\
\text { etc. } \\
\text { Respirable dose } \\
\text { dependent on } \\
\text { the dry powder } \\
\text { particle } \\
\text { properties } \\
\text { Moisture/electro } \\
\text { static attraction } \\
\text { may lead to } \\
\text { powder } \\
\text { aggregation, } \\
\text { changing } \\
\text { aerodynamic } \\
\text { properties } \\
\text { and/or causing } \\
\text { capsule } \\
\text { softening }\end{array}$ \\
\hline
\end{tabular}

Antimicrobial products for aerosol administration currently marketed and in clinical trials are outlined in Tables 2 and 3 respectively. 
Table 2: Approved antimicrobial aerosol preparations [42-46].

\begin{tabular}{|c|c|c|c|c|}
\hline FORMULATION NAME & ANTMICROBIAL & $\begin{array}{c}\text { DEVICE AND } \\
\text { DOSE } \\
\end{array}$ & ADVANTAGES & INDICATIONS \\
\hline $\begin{array}{c}\mathrm{TOBI}^{\circledR} \text { - Tobramycin } \\
\text { inhalation solution USP (TIS) } \\
\text { Novartis }\end{array}$ & $\begin{array}{c}\text { Tobramycin } \\
\text { Aminoglycoside }\end{array}$ & $\begin{array}{l}\text { Nebulization } \\
\text { PARI-LC } \\
\text { PLUS } \\
\\
300 \mathrm{mg} \\
\text { nebulized twice } \\
\text { daily }\end{array}$ & $\begin{array}{l}\text { Improved lung function, prevention of } \\
\text { pulmonary exacerbations }\end{array}$ & $\begin{array}{c}\mathrm{CF} \\
\mathrm{COPD} \\
\mathrm{CB} \\
\mathrm{VAP} \\
\mathrm{CAP}\end{array}$ \\
\hline $\begin{array}{c}\text { BRAMITOB }^{\circledR} \\
\text { Chiesi Farmaceutici }\end{array}$ & $\begin{array}{c}\text { Tobramycin } \\
\text { Aminoglycoside }\end{array}$ & $\begin{array}{c}\text { Nebulization } \\
\\
300 \mathrm{mg} \\
\text { nebulized twice } \\
\text { daily } \\
\end{array}$ & $\begin{array}{l}\text { Improved lung function, prevention of } \\
\text { pulmonary exacerbations }\end{array}$ & $\begin{array}{l}\mathrm{CF} \\
\mathrm{CAP}\end{array}$ \\
\hline $\begin{array}{c}\text { TOBI }^{\circledR} \text { - Tobramycin } \\
\text { PulmoSphere } \\
\text { powder USP } \text { inhalation } \\
\text { powP } \\
\text { Novartis }\end{array}$ & $\begin{array}{c}\text { Tobramycin } \\
\text { Aminoglycoside }\end{array}$ & $\begin{array}{l}\text { Podhaler } \\
112 \text { mg (28 } \\
\text { mg/capsule) } 4 \\
\text { capsules twice } \\
\quad \text { daily }\end{array}$ & $\begin{array}{l}\text { Improved lung function, well tolerated } \\
\text { and safe, prevention of exacerbations }\end{array}$ & $\begin{array}{c}\text { CF } \\
\text { COPD } \\
\text { CB } \\
\text { VAP }\end{array}$ \\
\hline $\begin{array}{c}\text { CAYSTONE } \\
\text { Aztreonam inhalation solution } \\
\text { (AZLI) } \\
\text { Gilead Sciences Inc. }\end{array}$ & $\begin{array}{l}\text { Aztreonam lysine } \\
\text { Monobactam }\end{array}$ & $\begin{array}{l}\text { PARI eFlow } \\
\text { nebulization- } \\
\text { Altera }{ }^{\circledR} \text { handset } \\
75 \text { mg thrice } \\
\text { daily }\end{array}$ & $\begin{array}{l}\text { Safe and efficacious in prevention of } \\
\text { lung exacerbations, no antibiotic } \\
\text { resistance evident, superior lung } \\
\text { function improvement to TIS }\end{array}$ & $\mathrm{CF}$ \\
\hline $\begin{array}{l}\text { COLOMYCIN }^{\circledR} \\
\text { Forest Laboratories }\end{array}$ & $\begin{array}{l}\text { Colistimethate } \\
\text { sodium } \\
\text { Polymyxin }\end{array}$ & $\begin{array}{c}\text { PARI eFlow }^{\circledR} \\
\text { nebulization } \\
\text { 80-160 mg twice } \\
\text { daily } \\
\end{array}$ & Eradication of P.aeruginosa & $\mathrm{CF}$ \\
\hline $\begin{array}{l}\text { PROMIXINE }^{\circledR}\left(\text { TADIM }^{\circledR}\right) \\
\text { Profile Pharma Ltd. }\end{array}$ & $\begin{array}{l}\text { Colistimethate } \\
\text { sodium } \\
\text { Polymyxin }\end{array}$ & $\begin{array}{c}\text { I-neb }^{\circledR} \text { AAD }^{\circledR} \\
\text { Nebulization } \\
\text { 80-160 mg twice } \\
\text { daily } \\
\end{array}$ & Eradication of P.aeruginosa & $\mathrm{CF}$ \\
\hline $\begin{array}{l}\text { COLOBREATHE }^{\circledR} \\
\text { Forest Laboratories }\end{array}$ & $\begin{array}{l}\text { Colistimethate } \\
\text { sodium } \\
\text { Polymyxin }\end{array}$ & $\begin{array}{c}\text { Turbospin } \\
\text { inhaler device- } \\
125 \mathrm{mg} \text { twice } \\
\text { daily }\end{array}$ & $\begin{array}{c}\text { Safe, well tolerated, efficacy similar to } \\
\text { TIS }\end{array}$ & $\mathrm{CF}$ \\
\hline $\begin{array}{c}\text { NEBUPENT }^{\circledR} \\
\text { APP Pharmaceutical, LLC }\end{array}$ & $\begin{array}{l}\text { Pentamidine } \\
\text { isethionate } \\
\text { Antifungal }\end{array}$ & $\begin{array}{l}\text { Respirgard } \circledast \text { II } \\
\text { Nebulizer } \\
\text { System } \\
300 \mathrm{mg} / 4 \text { weeks } \\
\end{array}$ & $\begin{array}{l}\text { Safer as compared to its parenteral } \\
\text { form Pentamidine } 300 \text { or Pentacarinat }\end{array}$ & $\begin{array}{c}\text { Pneumocystis carinii } \\
\text { pneumonia }\end{array}$ \\
\hline $\begin{array}{c}\text { AEROQUINTM } \\
\text { Levofloxacin inhalation } \\
\text { solution } \\
\text { (Aptalis Pharma, Inc/ Forest } \\
\text { laboratories) }\end{array}$ & $\begin{array}{c}\text { Levofloxacin } \\
\text { Fluoroquinolone }\end{array}$ & $\begin{array}{l}\text { PARI eFLOW } \\
\text { nebulization } \\
\\
\text { In study } 3 \text { dose } \\
\text { levels-120 mg or } \\
240 \mathrm{mg} \text { once } \\
\text { daily or } 240 \mathrm{mg} \\
\text { twice a day }\end{array}$ & $\begin{array}{l}\text { Decrease in P.aeruginosa density, } \\
\text { reduced need for other anti- } \\
\text { P.aeruginosa antibiotic, well } \\
\text { tolerated, broad spectrum activity } \\
\text { Similar efficacy to TOBI in CF } \\
\text { patients from Phase III clinical trial } \\
\text { studies }\end{array}$ & $\begin{array}{c}\mathrm{CF} \\
\mathrm{COPD}\end{array}$ \\
\hline
\end{tabular}


Table 3: Aerosol antibiotics in clinical trials [42, 43, 47, 48]

\begin{tabular}{|c|c|c|c|c|}
\hline FORMULATION NAME & ANTIMICROBIAL & $\begin{array}{l}\text { DEVICE AND } \\
\text { DOSE } \\
\end{array}$ & ADVANTAGES & INDICATIONS \\
\hline $\begin{array}{l}\text { ARIKAYCE }^{\mathrm{TM}} \\
\text { Liposomal amikacin for } \\
\text { inhalation } \\
\text { Insmed Inc. } \\
\text { (Phase III clinical trials) }\end{array}$ & $\begin{array}{l}\text { Amikacin } \\
\text { aminoglycoside }\end{array}$ & $\begin{array}{l}\text { PARI eFLOW } \\
\text { nebulization } \\
\begin{array}{c}\text { 560 mg once } \\
\text { daily }\end{array}\end{array}$ & $\begin{array}{c}\text { Sustained release of Amikacin, well } \\
\text { tolerable, reduction in P.aeruginosa } \\
\text { density }\end{array}$ & $\begin{array}{c}\mathrm{CF} \\
\text { Non-tuberculous } \\
\text { mycobacterial infections }\end{array}$ \\
\hline $\begin{array}{c}\text { ABELCETA } \hat{A}^{\circledR}(\text { Aerosolized } \\
\left.\text { Abelcet }^{\circledR}\right) \\
\text { Amphotericin B lipid complex } \\
\text { for nebulization } \\
\text { (Phase II clinical trials) }\end{array}$ & $\begin{array}{c}\text { Amphotericin B } \\
\text { Antifungal }\end{array}$ & $\begin{array}{l}50 \mathrm{mg} \\
\text { nebulized once } \\
\text { daily for four } \\
\text { days }\end{array}$ & $\begin{array}{c}\text { Reduction in parenteral side effects of } \\
\text { Abelcet }^{\circledR} \text { viz. nausea, vomiting, } \\
\text { disseminated fusariosis and }^{\text {withdrawal }}\end{array}$ & $\begin{array}{l}\text { Invasive fungal infections } \\
\text { in pediatric patients with } \\
\text { acute leukemia }\end{array}$ \\
\hline $\begin{array}{c}\text { CIPROINHALE } \\
\text { Ciprofloxacin PulmoSphere } \\
\text { inhalation powder (CPIP) } \\
\text { Bayer HeathCare } \\
\text { (Phase III clinical trials) }\end{array}$ & $\begin{array}{l}\text { Ciprofloxacin } \\
\text { Fluoroquinolone }\end{array}$ & $\begin{array}{c}\text { Powder } \\
\text { Inhalation } \\
\\
\text { In study at } 2 \\
\text { dose levels- } \\
32.5 \mathrm{mg} \text { or } \\
48.75 \mathrm{mg} \text { twice } \\
\text { daily }\end{array}$ & $\begin{array}{l}\text { High concentration in the lungs, } \\
\text { decrease in P.aeruginosa density }\end{array}$ & $\begin{array}{c}\text { CF } \\
\text { COPD } \\
\text { Non-CF bronchiectasis }\end{array}$ \\
\hline
\end{tabular}

\section{TYPES OF LUNG INFECTIONS}

Indigenous populations living in affluent countries are seriously affected by acute and chronic respiratory diseases resulting in a high burden to their health [49]. These diseases can be defined as any infectious diseases of the upper or lower respiratory tract, wherein, upper respiratory tract infections (URTIs) include common cold, tonsillitis, acute rhinosinusitis and acute otitis media. Lower respiratory tract infections (LRTIs) include acute bronchitis, bronchiolitis, pneumonia and tracheitis, and are a major health issue in many countries [49, 50]. Bacterial, fungal and viral infections occur frequently and play a crucial role in progression of chronic pulmonary diseases, such as COPD, $\mathrm{CB}, \mathrm{TB}$ and $\mathrm{CF}$ due to acute exacerbations leading to substantial long-term consequences, morbidity and mortality $[49,51,52]$.

\subsection{Bacterial infections}

Bacterial pathogens can be classified on the basis of their infection lifestyle in host and, hence can be either intracellularly or extracellularly located.

4.1.1 Extracellular pathogens- Most infections in CF, COPD, CB, etc., are caused by bacterial pathogens, such as Staphylococcus aureus, Escherichia coli and Pseudomonas aeruginosa. These organisms live extracellularly and hence are easier to eradicate than intracellular infections, which are present in special compartments, for instance alveolar macrophages and epithelial cells, where delivery of antibiotics faces greater challenges. Nevertheless, extracellular bacterial pathogens overcome antibiotic susceptibility by other means such as genetic modification and production of a sessile, slimy covering called a 'biofilm.' etc. [53]. These are explained briefly in the following sections.

Pseudomonal infections: Psuedomonal infections are clinically significant and can lead to life-threatening diseases and multiple organ failure [54]. Pseudomonas aeruginosa is the most prevalent of this class of pathogens and has been long associated with a variety of clinical problems. It is an opportunistic nosocomial pathogen and is the major infective organism leading to high mortality and morbidity in hospitalized patients $[54,55]$. It leads to sepsis in patients in the intensive care unit, and is also associated with mortality in cases of pulmonary hospital-associated pneumonia (HAP), namely ventilator-associated pneumonia (VAP) and bronchoscope-associated pneumonia [55]. This pathogen has also been associated with exacerbations of pulmonary conditions such as cystic fibrosis and COPD, primary bacteraemia in AIDS patients, malignant external otitis in diabetes', contact lens keratitis and traumatic endophthalmitis to name a few. It is also sometimes involved in pulmonary community-acquired pneumonia (CAP), being the third most common causative agent after Streptococcus pneumoniae and Legionella spp [55].

Pseudomonas aeruginosa and Cystic Fibrosis:

CF manifests a clinical syndrome exemplified by chronic infections affecting pulmonary, gastrointestinal, nutritional and urinary tracts leading to various abnormalities [56]. Pulmonary infections associated with CF are unique as they are characterized by various features, such as multiple host and parasite functions, metabolic disorder and restriction of infection to pulmonary tissue without any evidence of spreading systemically [57]. It is a severe monogenic 
autosomal recessive disorder arising from mutations in a single gene on the long arm of chromosome 7 which encodes the cystic fibrosis transmembrane conductance regulator (CFTR) protein. i.e. a member of ATP binding cassette family of transporters [56, 58, 59]. CFTR, a cAMP-regulated epithelial chloride channel, is a large glycoprotein channel expressed on epithelial cells largely responsible for $\mathrm{Cl}^{-}$ transport and also for transport of other ions, namely $\mathrm{Na}^{+}$and $\mathrm{HCO}_{3}$. Movement of water is also a function of this channel, maintaining fluidity in the various epithelial linings. In $\mathrm{CF}$ patients, viscid mucus is formed, due to CFTR dysfunction, which leads to a lack of transport of $\mathrm{Cl}^{-}$and water across the airway epithelium and excessive $\mathrm{Na}^{+}$reabsorption. This leads to formation of a dehydrated airway surface fluid (ASL)/ bronchoalveolar lavage (BAL) fluid. Viscid mucus leads to poor mucociliary clearance, entrapment of bacteria in the BAL fluid and inflammation $[56,58]$.

Despite an impressive understanding of the molecular basis and pathophysiology of the disorder, CF still prevails as a life-threatening genetic disorder causing many medical problems ultimately resulting in premature death $[56,59]$. Initially $\mathrm{CF}$ is associated with gastrointestinal disorders and pneumonia due to Staphylococcus aureus or Haemophilis influenza. However, these can be eradicated using antibiotics and patients lead a relatively normal life with appropriate gastrointestinal symptom control. With the advent of $P$. aeruginosa colonization, a myriad of medical disorders begin. There is rapid exacerbation and remission of the disease and formation of a large number of $P$. aeruginosa cells (up to $10^{8}$ organisms $/ \mathrm{ml}$ ) in the sputum and the extra mucus produced is sufficient to hold the pathogen at the pulmonary site, which cannot be killed by the alveolar macrophages on their own [60]. Additionally, P. aeruginosa adapts to anaerobic growth; obstruction of the bronchioles with mucus and low residual oxygen, leading to a low redox potential [57]. The organisms shed cell wall components, flagella, bacterial DNA and lipopolysaccharide all being immunostimulatory lead to a rapid proinflammatory response and formation of serotype-specific antibodies in the BAL fluid. However, these along with alveolar macrophages are ineffective in mediating opsonic uptake and killing of the pathogens. A study performed by Fick and colleagues showed that $P$. aeruginosa forms elastase which is capable of cleaving human $\mathrm{IgG}$ into fragments of less biological activity, such as $\left.\mathrm{Fab}, \mathrm{F}(\mathrm{ab})_{2}\right)_{2}$ and $\mathrm{Fc}$ which have been obtained from BAL fluids of CF patients. This has been shown to be the reason for failure of the host defence system in eradicating the pathogen. Rather, human host-defence systems lead to more damage due to loss of granular contents from phagocytic cells, polymorphonuclear accumulations, excessive interleukin- 8 and complement cleavage which leads to chronic inflammatory stimulus causing destruction of lung tissue [60].

Other microorganisms and Cystic Fibrosis:

Apart from the abundance of $P$. aeruginosa, other species of microorganism have been identified and isolated from the sputum and BAL of CF patients. These include other pseudomonal organisms, such as Pseudomonas maltophilia, Pseudomonas fluorescens, Pseudomonas alicaligenes and
Pseudomonas cepacia. The frequency of colonization by P.cepacia has increased greatly in the past decade. Infection leads to high fever, high leukocyte counts, pulmonary complications and is a causative agent leading to death in $\mathrm{CF}$ patients [57].

Other bacteria also found are Staphylococcus aureus, Haemophilus influenzae, Sreptococcus pneumoniae, Escherichia coli, Klebsiella spp, Proteus spp. etc. However these are not as chronic as the pseudomonal species. Acute exacerbations in $\mathrm{CF}$ are also associated with viruses, chlamydia and mycoplasmas. Fungal growths of Aspergillus fumigate and Candida albicans have also been isolated [57].

Pseudomonas aeruginosa and chronic obstructive pulmonary disease (COPD):

Chronic bronchitis is associated with cough and abnormal sputum production which on further complication leads to obstruction of the airways leading to COPD. COPD is the $3^{\text {rd }}$ leading cause of death in the United States and the $6^{\text {th }}$ worldwide [61, 62]. Pathogenesis of COPD is unknown; however, it has long been associated with cigarette smoking, inflammation and infections. Exacerbations of COPD lead to a reduction in health-related quality of life, increasing the cost of treatment, morbidity and ultimately mortality. Bacteria have been found to be the cause of acute exacerbation in $50-80 \%$ of COPD patients, predominately due to Streptococcus pneumonia, Haemophilus influenza and Moraxella catarrhalis, as well as other Gram-negative organisms such as Pseudomonas and Enterobacteriaceae spp $[61,62]$. $P$. aeruginosa is being investigated as a causative pathogen for exacerbations in severe COPD cases [63]. It has been isolated from $4-15 \%$ of adults with severe COPD requiring mechanical ventilation. COPD has been associated with increased bacterial mutation rates, increased resistance to antibiotics and greater biofilm production which is comparable to $\mathrm{CF}$ even though these two disease have completely different pathogenesis [63].

In COPD, airways inflammation with neutrophils and eosinophils has been evident in induced or expectorated sputum and BAL fluids. Neutrophils and eosinophil causing inflammation are associated with bacterial and viral infections respectively. Increased inflammation leads to increased bronchial tone with oedema in the bronchial wall and increased mucus production. Other clinical conditions associated with inflammation in COPD are cough, dyspnoea, increased sputum production and worsening of gas exchange due to loss in respiratory functions of the lungs [62].

Pseudomonas aeruginosa and Hospital-acquired pneumonia (HAP) and Community-acquired pneumonia (CAP):

For the past two decades there has been increasing prevalence of $P$. aeruginosa as a hospital-acquired pathogen. It is now the most frequently isolated Gram-negative organism from patient respiratory tracts and within intensive care units.

Pseudomonas aeruginosa has been isolated from the broncho-alveolar lavage (BAL) fluids of patients with Vapour-associated pneumonia (VAP). VAP caused by $P$. aeruginosa has a high mortality rate (32 to $43 \%$ ) even if patients are receiving appropriate antibiotic treatment [64]. 
Pseudomonas aeruginosa has also been associated with Bronchoscope-associated pneumonia. Bronchoscopes in hospitals, due to defects in their design, damage or improper disinfection provide an appropriate environment for growth of $P$. aeruginosa [64].

Pseudomonas aeruginosa has been associated with CAP being the third most common pathogen after Streptococcus aureus and Legionella pneumophila. However, it is associated with severe CAP that necessitates admissions to ICU, with an occurrence of $1.8-8.3 \%$ and a mortality rate of 50-100\% [64].

According to the guidelines laid by Infectious Disease Society of America/American Thoracic society (IDSA/ATS) and European Respiratory society (ERS), levofloxacin is recommended as a monotheraphy for CAP and in conjunction with $\beta$-lactam antibiotic for HAP. However, the choice of antibiotics is based on the causative organism [65]. 4.1.2 Intracellular pathogens: Eradication of intracellular infections faces challenges due to the difficulty of access in the protective environment within cells. Some organisms, such as mycobacteria spp., salmonella spp. and Neisseria spp. etc. are primary located in phagocytic intracellular compartments, including macrophages, polymorphonuclear leukocytes, neutrophils, etc. which recognize pathogenassociated molecular patterns (PAMPs) present on the surface of pathogens which are unique to the pathogen type. These proteins expressed on the pathogens are essential for their pathogenicity [66-70].

Mycobacterial infections: Tuberculosis (TB), a ubiquitous and highly contagious chronic bacterial infection caused by the bacillus Mycobacterium tuberculosis has re-emerged dramatically since the mid-1980s, particularly since the emergence of HIV infection, which renders the host 20-30 times more susceptible to infection by mycobacterium [71]. According to the WHO Global Tuberculosis Report 2013, TB affected about 8.6 million people in 2012, of which 1.3 million died from TB [72]. Additionally, strains of mycobacterium which are resistant to the first-line drugs, like isoniazid and rifampicin. have a high prevalence (3.6\%) amongst newly emergent TB cases worldwide [73]. Although TB can be both pulmonary and extrapulmonary, the pulmonary tract is a major portal of entry for mycobacterium, is the initial site of the immune response and is the site of resurgence of the disease. Mycobacterium tuberculosis has been shown to bind to and internalize into the alveolar macrophages, where it enhances its survival by suppression of macrophage immune responses ultimately leading to the pathogenesis of tuberculosis tuberculosis [68, $70,74]$, and spreads to cause extra-pulmonary TB which becomes very difficult to control.

\subsection{Fungal infections}

In the past few decades due to concurrent increases in organ transplantations, aggressive antineoplastic therapies, and immunocompromised patients; the prevalence and severity of pulmonary fungal infections has increased [75]. These infections have a lethality rate of $30-80 \%$ in immunocompromised and organ-transplant patients [76, 77]. The airways, being the major portal of entry of fungal spores, causing such infections, suggests direct pulmonary administration of anti-fungal agents to the lungs using inhaled drug delivery, could be an attractive way to treat invasive pulmonary fungal infections $[75,78]$.

Common fungal pathogens which infect the pulmonary tract are those that cause [79]:

(1) Invasive pulmonary aspergillosis- Aspergillus fumigatus, Aspergillus flavus, virulent species of Aspergillus terreus and A.astus that are resistant to treatment by azoles and amphotericin;

(2) Pulmonary candidiasis- Candida albicans

(3) Pulmonary mucormycosis- Rhizopus, Mucor and Rhizomucor spp

(4) Pulmonary cryptococcosis- $C$. gattii and $C$. neoformans

(5) Pulmonary blastomycosis- B. dermatitidis

(6) Pulmonary histoplasmosis- $H$. capsulatum

(7) Pulmonary coccidioidomycosis- Coccidioides immitis and C. posadasii [79]

Pneumocystis pneumonia has emerged as a serious healthcare problem due to the increased incidence of HIV which causes weakening of the patients' immune systems leading to infection with opportunistic fungus Pneumocystis jirovecii. This infection invades the alveolar lumen in the lungs of susceptible hosts, blocking oxygenation, leading to death [80].

\section{LIMITATIONS OF CURRENT ANTIMICROBIAL THERAPY}

\subsection{Intracellular pathogens}

Intracellularly bacterial infections are major causes of morbidity and mortality. Almost every bacterium has shown the ability to adapt and develop to form stronger and less susceptible variants to current antibiotic treatments, as evidenced by the high incidence of multi-drug resistant bacterial infections. This represents a considerable public health and economic burden as these variants are difficult to eradicate and more expensive to treat. This highlights the importance of developing new and improved methods of bacterial eradication. However, development of new chemotherapy approaches to combat the rapidly growing resistant strains of bacteria is too slow, threatening our ability to treat infectious diseases in the near future [81].

\subsection{Biofilms}

Microbiological research focuses predominantly on planktonic state cells, i.e. bacterial cells floating in culture to study antimicrobial activity. However it has now been established that in more than $80 \%$ of microbial infections the bacteria grow as a protected structured community of sessile cells encased in a self-produced hydrated polysaccharide slimy matrix [82-84]. Initially, a layer is formed at a surface, i.e. the foundation of the biofilm made up of organic/inorganic substances deposited and adhered to a substrate by gravitational sedimentation or settling. This provides nutrients and an anchor for the bacteria. Planktonic bacteria from the bulk liquid are then adsorbed and start 
forming micro-colonies onto this conditional layer by physical processes such as steric interactions, electrostatic interactions and Van der Waal forces or by bacterial appendages such as flagellae, pili and fimbriae. These then develop irreversible attachments by secretion of polysaccharide intercellular adhesion proteins and divalent cations that consolidate the surface-bacteria bond. These structures contain channels in which nutrients for the bacterial cells are circulated, and hence there is a rapid population growth of daughter sessile bacterial cells which adapt to the biofilm environment by changes in the expression of genes and in the surface properties of bacterial cells, and grow together in nascent clusters. The final stage of biofilm development is completed by quorum sensing (QS) cell signalling mechanisms, wherein stimulation of genetic expression takes places leading to production of alginate which forms a part of the extracellular matrix of the biofilm, along with many other signal molecules that help in co-ordination of the biofilm bacteria. These signals govern processes such as bacterial dispersion which is essential to prevent overgrowth of the rapidly dividing bacteria, and their escape and colonization of new niches when nutrients become limited and waste products accumulate [85].

Numerous mechanisms are involved in the avoidance of antibiotic challenges by biofilm-associated bacteria. One mechanism is the failure, retardation or reduction in penetration and diffusion of antibiotics into the full depth of the biofilm due to the presence of a physical polymeric barrier. A further mechanism is a change in the microenvironment of the biofilm. Studies have shown that there are anaerobic niches in the deeper regions of the biofilms, rendering some antibiotics, such as those of the aminoglycoside class inactive. Moreover, accumulation of waste products may cause a change in the $\mathrm{pH}$ of the biofilm niche which can directly cause inactivation or antagonism of certain antibiotics, limiting their activity. Additionally alteration in the osmotic environment leads to an osmotic stress response, ultimately resulting in a reduction in the permeability of bacteria to antibiotics by altering the proportion of porins in the bacterial cell wall. A further proposed mechanism to explain reduced biofilm susceptibility is the development of slow-growing or nongrowing dormant bacterial cells which become less susceptible to antibiotics, e.g. penicillin antibiotics which target cell-wall synthesis bacteria [82, 83].

\subsection{Bacterial resistance}

Historically, treatment failures to antibiotics due to resistance were not given a great deal of importance as other antibiotic classes were available. However, relatively quickly multiple resistance to numerous antibiotic developed, which now represents a considerable therapeutic challenge. The first global report on antibiotic resistance by the WHO in 2014 revealed a serious threat worldwide and the need for urgent interventions to combat an imminent future crisis [86]. Multi-drug resistant tuberculosis (MDR-TB) has emerged swiftly, representing a global health concern, threatening TB control and treatment worldwide [87]. WHO has reported a doubling in the people diagnosed with MDRTB between 2011 and 2012, with 0.45 million new incidences of MDR-TB and an occurrence of 0.17 million deaths in 2012 due to MDR-TB [72, 73]. Instances of extensively drug resistant (XRD-TB) and totally drug resistant (TDR-TB) cases have risen persistently in the past decade, posing a major challenge to the limited, time consuming treatment options currently available to treat TB. Bacterial resistance to antibiotics can be innate or acquired by genetic and phenotypic modifications. A speculative hypothesis explaining reduced antibiotic susceptibility is the development of resistance due to genetic chromosomal mutations of the bacteria. These can result in (1) reduced permeability or uptake of the antibiotic, e.g. resistance to chloramphenicol antibiotics due to decreased permeability into Gram-negative bacteria. Resistance to penicillin and tetracycline is evident in Neisseria gonorrhoea due to reduced permeability of the antibiotics [88]; (2) increased efflux activity of the antibiotic from the bacterial cell, e.g. in the presence of tetracycline, the $\operatorname{Tet} K$ gene responsible for efflux, transcription and translation is activated leading to an increase in the number of efflux pumps and consequently resistance to tetracycline antibiotics [89]. Up-regulation of the norA gene in $S$. aureus leads to an increase in efflux pumps leading to fluoroquinolone antibiotic resistance; (3) enzymatic inactivation of antibiotics, e.g. $\beta$-lactamases catalysing ring-opening of $\beta$-lactam antibiotics. Aminoglycoside antibiotics are inactivated by addition of acetyl, adenyl and phosphoryl groups onto the antibiotic by aminoglycoside-inactivating enzymes [90]; (4) alteration of the drug target site, e.g. alterations in the target site of DNA gyrase subunit A and B are responsible for resistance against fluoroquinolone antibiotics [91]. Resistance against rifampicin arises from mutation in the $\beta$ sub-unit of the RNA polymerase site required by the drug to show activity. Streptomycin resistance has been evident due to target site mutation on the rrs gene encoding 16s rRNA [92], and (5) loss of enzymes necessary for activation of the antibiotic, e.g. inactivation of the katG gene leads to reduced catalase activity and hence ineffective conversion of isoniazid into its active hydrazine derivative. Inactivation of pyrazinamidase by mutation in the $p n c A$ gene required for conversion of pyrazinamide to its active form pyrazinoic acid results in loss of antimycobacterial activity of the antibiotic [93, 94].

Further, phenotypic modifications involve sessile bacteria in biofilms that grow as spore-like biologically programmed bacterial subpopulations which are unique and highly protected dormant phenotypes, which are resistant to antibiotics in the dormant state. Another type of phenotypic modification involves the presence of salicylates, such as aspirin which make bacteria, including Pseudomonas, Mycobacterium tuberculosis and E.coli etc. less susceptible to common antibiotics due to an increased antibiotic efflux and reduced permeability, by a reduction in the level of porin expression [95].

\subsection{Sputum}

Mucus in the healthy lung is $10-30 \mu \mathrm{m}$ thick in the trachea and 2-5 $\mu \mathrm{m}$ thick in the bronchial regions. This thickness allows easy diffusion of gas, nutrients, ions, proteins, etc., and the entrapment of particulate matter which is then efficiently removed by the mucociliary clearance process. 
Chronic lung diseases, such as COPD, chronic bronchitis, asthma and $\mathrm{CF}$ are associated with impaired mucociliary clearance and necrotic death of epithelial and inflammatory cells in patients' lungs leading to bronchiectasis and deposition of thick, stationary, tenacious mucus plaques where heavy colonization of bacteria especially by $P$. aeruginosa is evident, due to the availability of a nutrient rich environment that is optimal for bacterial growth [9698]. This viscoelastic and adhesive mucus secretion acts as a physical barrier and hinders diffusion of antibiotics and acts as an electrostatic barrier. Necrotic cells contribute to excess release of a network of copolymerized polyanionic contents including DNA, mucin glycoproteins and F-actin which physically bind to polycationic antibiotics, such as tobramycin leading to their deactivation [96, 98, 99]. Antibiotics delivered for treating bacterial infections associated with these diseases needs to penetrate the sputum and distribute evenly. Drugs such as ion-channel modulators or gene therapeutics which need to reach the epithelial layer must first traverse the thick mucus layer to achieve their desired activity $[100,101]$.

There are steep hypoxic gradients in the airway sputum which have been shown to activate the genes responsible for anaerobic respiration of $P$. aeruginosa, and hence cause a conversion of the bacteria from the non-mucoid to the resistant extracellular polymeric substance (EPS)-producing mucoid mutant $[98,102,103]$. This mucoid mutant secretes alginate in which microcolonies of the bacteria are embedded, providing increased resistance to phagocytes, opsins and antibiotics [98, 102-104]. The increased presence of mucin glycoproteins in the sputum of patients immobilizes $P$. aeruginosa by surface interactions, which has increased tolerance to antibiotics resisting clearance from these hypoxic mucopurulent masses in the airway $[98,105]$. The CF sputum is the reason for failure of drug delivery and hence treatment [100, 101]. Moreover, antibodies and fragments along with other soluble factors act as molecular traps for viral gene delivery, as demonstrated for adenoviral gene delivery due to the presence of adenoviral antibodies [100].

\section{DRUG DELIVERY SYSTEMS}

Researchers have made great advances in engineering new nanotechnology-based carrier systems for different pulmonary applications. The choice of delivery system largely depends on factors such as:

Disease condition: This is a crucial parameter which dictates the choice of delivery system. For different disease conditions, varied formulations are required to transport the drug to the particular site of action and impart desired pharmacological effect. Delivery of water insoluble drugs and highly unstable drug molecules may be achieved by loading them into nano-delivery systems. For the systemic delivery of insulin for the treatment of Diabetes Mellitus, nanoparticle dry powders have been marketed as Exubera ${ }^{\circledR}$ (Pfizer; now withdrawn) and Afrezza ${ }^{\mathrm{TM}}$ (MannKind) which is a Technosphere ${ }^{\mathrm{TM}}$-based inhaled insulin product. Both of these need to be deposited in the alveoli, and hence require an optimized delivery device [106-108]. On the other hand, local administration of anti-tubercular drugs needs a delivery system which not only transports drug to the alveolar macrophages but also has the capacity of being endocytosed by these macrophages [106]. However, endocytosis of $\beta$ agonists leads to their inactivation and clearance leading to loss of efficacy, hence formulations with minimal macrophage uptake properties would be needed [106]. Delivery of nanoparticles encapsulating antibiotics to the lung for treatment of infections associated with $\mathrm{CF}$, COPD or pneumonia etc. can present a great challenge due to the thick viscoelastic mucus barrier in the lung. To traverse this barrier, nanoparticles must have a small size and should ideally be designed with a muco-inert surface so as to prevent their adhesion to mucin fibres which are highly prevalent and pose as a severe hurdle to delivery of antibiotics to the site of infection in these disease conditions [109].

Retainment of pharmacological effect: The formulation and preparation of the delivery system should not affect the pharmacological activity of the drug. The release profile of the drug should be optimized to achieve maximum drug efficacy and duration of activity [108].

Fate of delivery system: This is important criterion needs careful consideration. Varied delivery system engineering parameters, such as shape, size, materials, aggregation state, surface charge, chemical properties, formulation, etc. may each affect the toxicity profiles [110]. The small size of these new delivery systems imparts them with new physical and chemical properties different from conventional bulk drug powders [111]. It has been observed that multi-walled carbon-nanotube based delivery systems have the capacity to collect in the subpleural regions of the lung, leading to pulmonary fibrosis, multifocal granulomatous inflammation, diffuse histiocytic and neutrophilic inflammation, intraalveolar lipoproteinosis etc. $[110,112]$. Inhaled nanoparticles can not only cause inflammation and other exacerbations, but may also interfere with the functioning of the pulmonary system. Nanoparticles fabricated of polystyrene, gold or titanium dioxide have been reported to alter the function and structure of pulmonary surfactant and hence impede its ability to decrease surface tension rapidly during a normal breathing cycle [113]. Clearance of nanoparticles in alveolar region is mediated by alveolar macrophages. These recognize nanoparticles, phagocytize them, travel to the mucociliary escalator and are cleared. However, this process is very slow and the retention half-life of solid particles deposited in the alveolar region of humans is 700 days. Moreover, larger particles are not easily phagocytized nor are ultrafine nanoparticles [114].

The various delivery systems which can be used to deliver antimicrobials to the site of infection in the lung are:

\subsection{Liposomes}

Liposomes are lipid-based carrier systems which have been widely used as drug carriers for cosmeceutical and pharmaceutical applications and are the most studied delivery system for the delivery of a variety of therapeutics $[115,116]$. Liposomes are self-assembling structures which due to intrinsic interfacial properties imparted by the 
phospholipids spontaneously form spherical vesicles in aqueous media. These vesicles are made up of one or more concentric phospholipid bilayers alternating with aqueous compartments, with sizes ranging from 0.05-50 $\mu \mathrm{m}$. Hydrophobic and amphiphilic drugs can be incorporated within the lipid bilayers, whereas, hydrophilic drugs can be encapsulated in the aqueous compartments/core. They are safe, non-toxic, biodegradable, biocompatible delivery systems for encapsulation of a wide range of drugs having varied properties, including molecular size, charge, hydrophobicity etc. They interact with living cells by adsorption, endocytosis, lipid exchange and/or fusion [116118]. Liposomes can be divided into categories based on the basis of their size and lamellarity; namely small unilamellar vesicles (SUV), large unilamellar vesicles (LUV) and multilamellar vesicles (MLV), or on the basis of their properties, for instance immunoliposomes, stealth liposomes, proteoliposomes, $\mathrm{pH}$-sensitive liposomes, charged liposomes etc. $[116,117,119]$. Liposomes can be prepared using a number of techniques, the most frequently used of which are the thin-film method, reverse-phase evaporation, solvent injection, freeze-thaw extrusion and ultrasonication [119].

\section{Liposome delivery to the lung:}

These are an attractive delivery system to the lung as they can be made of surfactants which are endogenous to the pulmonary tract. The first pulmonary-delivered liposomal product being Alveofact ${ }^{\circledR}$ (LyomarkPharma), instilled to the lung for treatment of pulmonary distress syndrome. Deposition of liposomes, aerosolized with jet nebulizers, into the non-ciliated peripheral regions of the lung results in prolonged greater retention of the liposome-associated drug within the lung $[120,121]$. Cationic liposomes have been successful in aerosol delivery of gene [114, 122, 123], while liposomes conjugated with cell-penetrating peptides can act as potential carriers of macromolecules to the lungs [114]. Modification of the liposome surface with Ostearylamylopectin has been shown to increase lung tissue affinity [116], while conjugation of liposomes with octaargine or antennapedia enhanced cellular uptake in the airway [114]. Conjugating mannose to liposomes produces superior macrophage uptake to non-conjugated liposomes, with potential application in the treatment of diseases such as rheumatoid arthritis, tuberculosis, leishmaniasis, etc. where the macrophages play a very important role in the disease $[124,125]$. Stability of the vesicles, vesicle delivery and the size properties of the aerosol cloud are major considerations when atomizing liposomes using nebulizers, and are functions of both formulation properties and the nebulizer system employed. Bridges et.al [126] showed the significance of lipid concentration in determining the droplet size of the aerosols generated from two different jet nebulizers, namely Pari-LC and Sidestream. Increasing the egg phosphatidylcholine/cholesterol lipid concentration from 5 to $80 \mathrm{mg} / \mathrm{ml}$ led to a reduction in output of the liposomes from both the nebulizers for liposomes of $5 \mu \mathrm{m}$, with the mean droplet size of the aerosol generated being $2 \mu \mathrm{m}$. Whereas fluid liposomes could be size reduced in the nebulizer and delivered in the aerosol, rigid liposomes failed to be aerosolized, whilst increased lipid concentrations resulted in a rise in viscosity with subsequent reduction in aerosolization [126]. Bridges et al [120] also highlighted the importance of liposomal constituents for determining the damage caused to liposomes during nebulization by ultrasonic and jet nebulizers. Fluid egg phosphatidylcholine liposomes were size reduced on aerosolization using both devices, which will cause loss of entrapped hydrophilic drugs, whilst incorporation of cholesterol or use of lipids which having a high phase transition temperature, such as DPPC imparted rigidity to the bilayers, resulting in liposomes more resistant to the shearing forces occurring during aerosolization [120]. Chattopadhyay et al [127] highlighted the importance of bilayer composition, namely neutral or charged lipids and presence of cholesterol on the morphology and bilayer integrity of small liposomal suspensions, size range $80-130 \mathrm{~nm}$, nebulized using a jet nebulizer. Aerosolization of the liposomes consisting of DPPC, DSPG (charged lipid), DPPC:DSPG:DSPE-PEG and DPPC:DSPG:Chol demonstrated that addition of charged lipids reduced aggregation due to electrostatic repulsion during nebulization, as compared to uncharged liposomes (DPPC), however, such liposomes had a greater loss of encapsulated dye due to increased membrane rupture. On the other hand, addition of cholesterol along with the charged lipid (DPPC:DSPG:Chol) helped in reduction of aggregation and higher retention of dye (>85\%) [127]. Studies have emphasized the importance of the nebulizer used in conjunction with liposomal systems. Use of a vibrating mesh nebulizer Aeroneb ${ }^{\circledR}$ for aerosolization of DPPC liposomes encapsulating Iloprost for pulmonary arterial hypertension showed significant advantages due to reduced drug loss and change in liposomal size compared the jet nebulizer Pari LC $^{\circledR}$ star or ultrasonic nebulizer Optineb ${ }^{\circledR}$ [128]. The relationship between nebulizer performance and formulation development requires in-depth knowledge of formulation properties and the working principles of the various nebulizer types. An attractive approach would be to deliver liposomes by DPIs produced by spray drying the liposomes and relying on their hydration in situ on delivery to the moist airways [129, 130].

\section{Liposomes and antimicrobials:}

The properties of liposomes can be easily manipulated and a variety of including antimicrobials can be incorporated within them. By encapsulating antimicrobials into liposomes, improved delivery may be achieved, for instance by targeting macrophages where infections reside, or due to their small size they can pass through biofilms and reach peripheral sites for complete bacterial eradication [117, 131]. Rifampicin, an anti-mycobacterial drug used for tuberculosis treatment shows a very high rate of hepatotoxicity and nephrotoxicity, along with other side effects, including thrombocytopenia, immune haemolytic anemia and intravascular haemolysis due to its high metabolism in these organs leading to idiosyncratic metabolites which are toxic to these organs on oral delivery [132-136]. Encapsulation of rifampicin into pulmonary-delivered liposomes improves its toxicity profile and reduces hepatotoxicity [137-139]. Various liposomal systems for pulmonary delivery of antifungals, antimycobacterials and other antimicrobials have been 
described in literature, a few of which have reached clinical trials, as summarized in Table 4.

Table 4: Liposomal antimicrobial therapies under investigation.

\begin{tabular}{|c|c|c|}
\hline ANTIBIOTIC & MICROORGANISM & ADVANTAGES \\
\hline $\begin{array}{c}\text { Amikacin } \\
\text { Aminoglycoside } \\
\text { DPPC:Chol liposome } \\
\text { ARIKAYCETM } \\
\text { Clinical trials phase III }\end{array}$ & $\begin{array}{l}\text { Pseudomonas aeruginosa } \\
\text { (Inhalation-nebulization) }\end{array}$ & $\begin{array}{l}\text { Comparison of Arikayce }{ }^{\mathrm{TM}} \text { versus placebo nebulized to the lungs showed beneficial } \\
\text { results as liposomal amikacin had susceptibility to cross mucus and biofilm present in } \\
\text { patients suffering from CF, hence, sustained and significant improvement in lung } \\
\text { function and reduction of pseudomonas density [140] }\end{array}$ \\
\hline $\begin{array}{c}\text { Amikacin } \\
\text { Aminoglycoside } \\
\text { HSPC:Chol:DSPG (2:1:0.1) } \\
\text { MiKasome® (NeXstar } \\
\text { Pharmaceuticals, Inc) } \\
\end{array}$ & Mycobacterium tuberculosis & $\begin{array}{l}\text { Increased uptake by the mononuclear phagocyte system showed benefits especially for } \\
\text { multi-drug resistant M.avium, wherein, increased killing is evident versus free amikacin } \\
\text { which fails to reach high intracellular effects and shows ototoxicity and nephrotoxicity } \\
\text { [141-144] }\end{array}$ \\
\hline $\begin{array}{l}\text { Tobramycin } \\
\text { Aminoglycoside } \\
\text { Fluidosomes } \\
\text { (Axentis Pharma) } \\
\text { Clinical Trial II } \\
\end{array}$ & $\begin{array}{l}\text { Pseudomonas aeruginosa } \\
\quad \text { Escherichia coli } \\
\text { Staphylococcus aureus [116] }\end{array}$ & $\begin{array}{l}\text { Improved management of pulmonary infections was seen on intratracheal administration } \\
\text { of fluid-based liposomes encapsulated tobramycin [145] }\end{array}$ \\
\hline $\begin{array}{c}\text { Riampicin+ Isoniazid } \\
\text { DPPC:Chol } \\
\text { Passively targeted } \\
\end{array}$ & Mycobacterium tuberculosis & $\begin{array}{l}\text { Increased therapeutic drug level found in the plasma on inhalation administration of a } \\
\text { single dose in guinea pigs } \\
\text { Drugs found to localize in the alveolar macrophages of the lungs }[146,147]\end{array}$ \\
\hline $\begin{array}{c}\text { Rifampicin+ Isoniazid } \\
\text { DPPC:Chol:O- } \\
\text { stearylamylopectin: DCP:DSPC- } \\
\text { PEG 2K } \\
\text { Actively targeted } \\
\end{array}$ & Mycobacterium tuberculosis & $\begin{array}{c}\text { Superior efficacy of the formulations against M.tuberculosis with a reduction in } \\
\text { mycobacterial CFUs in liver, kidney and lungs. } \\
\text { Reduction in nephrotoxicity associated with the free drug and normal lung morphology } \\
\text { observed }[137,146,148]\end{array}$ \\
\hline $\begin{array}{c}\text { Rifampicin } \\
\text { Egg PC:Chol:O- } \\
\text { stearylamylopectin:DCP or } \\
\text { Egg PC:Chol: maleylated bovine } \\
\text { serum albumin: DCP } \\
\text { Actively targeted }\end{array}$ & Mycobacterium tuberculosis & $\begin{array}{l}\text { The targeted liposomes showed improved lung accumulation specifically improved } \\
\text { alveolar macrophage uptake and accumulation showing the feasibility of the inhalatory } \\
\text { mode of delivery for eradication of M. tuberculosis. }[146,149]\end{array}$ \\
\hline $\begin{array}{l}\text { No drug specified } \\
\text { HSPC:Chol:DCP:MAN } \\
\text { Actively targeted }\end{array}$ & - & $\begin{array}{l}\text { Significantly higher internalization and selective targeting to alveolar macrophages in } \\
\text { vivo with the mannose- linked liposomes compared to non-targeted liposomes [146, 150, } \\
151] \text {. }\end{array}$ \\
\hline $\begin{array}{l}\text { Ciprofloxacin } \\
\text { Fluoroquinolone }\end{array}$ & $\begin{array}{l}\text { Pseudomonas aeruginosa } \\
\text { Francisella tularenis } \\
\text { Brucella melitensis }[116]\end{array}$ & $\begin{array}{c}\text { Reduction of efflux mechanism and increased bacterial retention as compared to free } \\
\text { drug on aerosol inhalation } \\
\text { Free drug was ineffective in treating } F \text {. Tularenis }[152]\end{array}$ \\
\hline $\begin{array}{c}\text { Polymyxin B } \\
\text { Peptide antibiotic }\end{array}$ & Pseudomonas aeruginosa & $\begin{array}{l}\text { Intratracheal instillation of liposomal polymyxin B showed higher drug amounts, greater } \\
\text { retention and pronounced protective effects in lungs as compared to free polymyxin B } \\
\text { and protection from nephrotoxicity, ototoxicity and neuromuscular blockade }[118,153]\end{array}$ \\
\hline $\begin{array}{l}\text { Dapsone } \\
\text { Sulphone antibiotic }\end{array}$ & $\begin{array}{l}\text { Pneumocystis } \\
\text { carinii } \text { pneumonia }\end{array}$ & $\begin{array}{c}\text { Dapsone nanoliposomes based DPI showed enhanced drug release with deep lung } \\
\text { penetration due to increase in fine particle fraction to } 75 \% \text { reducing systemic toxicity and } \\
\text { promising better treatment }[140,154]\end{array}$ \\
\hline $\begin{array}{c}\text { Ciprofloxacin-Fluoroquinolone } \\
\text { or } \\
\text { Azithromycin-Macrolide }\end{array}$ & Mycobacterium avium & $\begin{array}{l}\text { 43-fold greater potency was seen against M.avium compared to free ciprofloxacin due to } \\
\text { increased negative charge imparted by the liposome formulation of DSPG:Chol [117, } \\
155]\end{array}$ \\
\hline
\end{tabular}

CF- cystic fibrosis, TB- Tuberculosis, DPI- dry powder inhalation, DSPG- distearoylphosphatidyl glycerol, DCP- dicetyl phosphate, HSPC-hydrogenated Soy Phosphatidylcholine, Egg PC- egg Phosphatidylcholine, Chol- cholesterol, MAN- mannose, CFUs- colony forming units 


\subsection{Polymeric microparticles and nanoparticles}

Microparticles are in the micrometer size range and can be classified as microspheres i.e. uniform spheres constructed of polymeric matrices, or microcapsules i.e. a thin polymer membrane encapsulating an oily core [156]. Nanoparticles

can also be used for pulmonary delivery; however, due to their small size they may be exhaled and hence not deposit in the airways. To overcome this drawback they can be delivered by nebulization after suspending in a suitable liquid, with deposition governed by the size characteristics of the nebulized droplets, or incorporated into larger carrier particles [157]. Microparticles are used as an alternative to liposomes, being more readily stable on storage or in the biological fluids, and they offer the possibility of modulation of release rate [158].

Polymers are used in different fields such as pharmaceutical, biomedicine, tissue engineering, cosmeceuticals, etc. [159]. Polymeric microspheres prepared from biodegradable or biocompatible, natural or synthetic polymers have been studied as delivery systems for pulmonary delivery, to control delivery of drugs to the pulmonary tract and to protect them from enzymatic degradation. Polymer selection is critical for the success of the formulation, with appropriate control of drug release. As for all pulmonary delivery, the size of the nanoparticles and microparticles and their adequate dispersion a critical to ensure deep lung delivery [156, 157]. Particulate systems have a number of key parameters, including morphology, size, size distribution, porosity, density, surface charge, surface energy, controlled or sustained release etc. which are functions of many variables to be considered in their formulation and manufacture, such as: polymer lengths, surfactants, organic solvent, preparation methods, etc. A wide range of natural polymers, for instance albumin, collagen and chitosan are available, however users must consider a potential lack of purity, the presence of homogeneity and the possibility of disease transmission. However, these natural polymers can be modified, for instance the acylation of chitosan, to control release rate. Synthetic polymers, like poly(lactide-coglycolide) (PLGA) copolymers, polyacrylates, poly(lactic) acid (PLA), poly(butylcyanoacrylate) and poly(lactic-colysine) graft polymers and polyanhydrides are available and offer advantages over natural polymers as they can provide sustained/controlled release, and have high purity, homogeneity and other desirable properties [153, 156-158]. Targeting can also be achieved by using ligands. For instance, lectin may be used with polymeric microspheres, as it binds to simple/complex carbohydrates on bacterial cell walls, and it has been used against Helicobacter pylori infections by conjugation onto gliadin nanoparticles [153]. Polymeric nanoparticles can be prepared by various methods namely: emulsification-solvent removal, phase coacervation, interfacial polymerization and spray drying. The choice of method depends on the desired size and properties of microsphere to be made, and physiochemical properties of drug [158].

The mechanism of drug release from nanoparticles is due to degradation or erosion of the polymeric matrix. If the polymer matrix undergoes degradation, it releases by diffusion due to polymeric chain breakage leading to channels created in matrix. Erosion of polymer matrix leads spontaneous drug release as the polymer is eroded [158, 159]. Technical and stability issues regarding the use of nanoparticles for delivery of anti-infective agents to the lung however prevail. To date, most nanoparticles have been aerosolized using nebulizers. However, storage of colloidal preparations results in instabilities, such as polymer hydrolysis, drug loss, particle-particle interaction of nano/microparticles and particle aggregation. Previous studies have highlighted the importance of formulation development and nanoparticle size on aerosol size and the incorporation of particles into nebulized droplets. In addition to size, the surface properties of individual particles and their concentration play an important role in determining formulations release kinetics and the output from the nebulizer [160-162]. Dry powder inhaler formulations can be achieved by spray drying nanoparticle and microparticle dispersions, and this can be an attractive alternative approach to ensure the long-term stability of nano/microparticles. However, redispersion on aerosolization and in the pulmonary fluid are important criteria, and retention of the nano/micropaticle size in the lungs post-aerosolization can be a challenge [162].

Polymeric nanoparticles described in literature for pulmonary applications in infective disease are summarized in Table 5.

Table 5: Polymeric microparticles described in literature for delivery of antimicrobials for treating pulmonary infections.

\begin{tabular}{|c|c|c|c|}
\hline POLYMER & ANTIMICROBIAL & MICROORGANISM & ADVANTAGES \\
\hline $\begin{array}{c}\text { Polybutyl cyanoacrylate } \\
\text { nanoparticle } \\
\text { (PBCA) }\end{array}$ & $\begin{array}{l}\text { Rifampicin } \\
\text { Antimycobaterial }\end{array}$ & $\begin{array}{l}\text { Mycobacterium avium } \\
\text { Staphylococcus aureus }\end{array}$ & $\begin{array}{l}\text { 2-3 fold greater delivery of rifampicin loaded-PBCA to the alveolar } \\
\text { macrophages leading to } 2 \text {-fold increase in rifampicin efficacy } \\
\text { compared to free rifampicin }[153,163]\end{array}$ \\
\hline $\begin{array}{l}\text { PLGA- Nanoembedded } \\
\text { microparticles }\end{array}$ & $\begin{array}{l}\text { Tobramycin } \\
\text { Aminoglycoside }\end{array}$ & $\begin{array}{l}\text { Pseudomonas } \\
\text { aeruginosa }\end{array}$ & $\begin{array}{l}\text { PLGA-tobramycin nanoparticles embedded in respirable lactose } \\
\text { microparticles and consisting of helper polymers like chitosan } \\
\text { showed greater mucin interactions and behaved as drug reservoirs to } \\
\text { achieve sustained drug release [164] }\end{array}$ \\
\hline
\end{tabular}




\begin{tabular}{|c|c|c|c|}
\hline $\begin{array}{l}\text { Poly(lactide-co-glycolide) } \\
\text { (PLGA) }\end{array}$ & $\begin{array}{l}\text { Ciprofloxacin } \\
\text { Fluoroquinolone }\end{array}$ & $\begin{array}{l}\text { Staphylococcus aureus } \\
\text { Pseudomonas } \\
\text { aeruginosa }[140,153]\end{array}$ & $\begin{array}{l}\text { Nano-ciprofloxacin formulations achieved sustained release of drug } \\
\text { directly at the site of pulmonary infection and appropriate } \\
\text { aerodynamic particle size to achieve deep lung access for the drug } \\
{[140,165]}\end{array}$ \\
\hline $\begin{array}{l}\text { Polyisobutyl cyanoacrylate } \\
\text { (PIBSA) }\end{array}$ & $\begin{array}{c}\text { Ciprofloxacin } \\
\text { Fluoroquinolone } \\
\end{array}$ & Mycobacterium avium & $\begin{array}{l}\text { IV administration of Ciprofloxacin loaded- PIBSA showed greater } \\
\text { activity due to higher uptake in alveolar macrophages compared to } \\
\text { free ciprofloxacin [117] }\end{array}$ \\
\hline $\begin{array}{c}\text { Albumin, } \\
\text { dipalmitoylphosphatidylcholine } \\
\text { and lactose (DAL) }\end{array}$ & $\begin{array}{c}\text { Ceftazidime } \\
\text { Cephalosporin } \\
\text { Ciprofloxacin } \\
\text { Fluroquinolone }\end{array}$ & $\begin{array}{c}\text { Pseudomonas } \\
\text { aeruginosa }\end{array}$ & $\begin{array}{l}\text { DAL based ceftazidime and ciprofloxacin showed better stability } \\
\text { than nebulized solutions in which these drugs precipitate, successful } \\
\text { co-deposition at desired site in desired ratio, improved aerodynamics } \\
\text { and additive antipseudomonal activity was achieved [166] }\end{array}$ \\
\hline Carboxymethyl chitosan (CMC) & $\begin{array}{l}\text { Ciprofloxacin } \\
\text { Fluoroquinolone } \\
\end{array}$ & Escherichia coli & $\begin{array}{l}\text { 2-fold increase in antibacterial activity of ciprofloxacin loaded CMC } \\
\text { compared to free ciprofloxacin was seen due to increased bacterial } \\
\text { uptake [167] }\end{array}$ \\
\hline
\end{tabular}

\subsection{Lipid microparticles and nanoparticles- Solid lipid nanoparticles}

Lipid microspheres and nanospheres may be used as an alternative to polymer microspheres and liposomes. Solidlipid nanoparticles (SLNs) range from 50-100 $\mathrm{nm}$ and have attracted attention in the past 25 years due to the easy fabrication techniques. SLNs are viewed as a potential pulmonary delivery system due to the low toxicity of phospholipids employed, compared to polymer-based systems, higher tolerability in lungs, prolonged and controlled release properties and rapid in-vivo degradation compared to PLGA or PLA particles. Their composition includes: fatty acids, steroids, triglycerides, partial glycerides, waxes that are solids at room temperature as well as surfactants to stabilize the SLNs. They can be prepared by simple spray drying, ultra-sonication and high pressure homogenization as dry powders or dispersions for delivery via a nebulizer $[114,153]$. Lipid microparticles and nanoparticles described in literature are summarized in Table 6.

Table 6: Solid lipid nanoparticles described in literature for delivery of antimicrobials for treatment of pulmonary infections.

\begin{tabular}{|c|c|c|c|}
\hline SOLID LIPID & ANTIMICROBIAL & MICROORGANISM & ADVANTAGES \\
\hline $\begin{array}{c}\text { Stearic acid, soya, } \\
\text { phosphatidyl choline and } \\
\text { sodium taurocholate }\end{array}$ & $\begin{array}{c}\text { Tobramycin } \\
\text { Aminoglycoside }\end{array}$ & $\begin{array}{c}\text { Pseudomonas } \\
\text { aeruginosa }\end{array}$ & Increased drug bioavailability and prolonged drug release [153] \\
& $\begin{array}{c}\text { Ciprofloxacin } \\
\text { Fluoroquinolone }\end{array}$ & $\begin{array}{c}\text { Mycobacterium } \\
\text { tuberculosis } \\
\text { pyrazinamide- } \\
\text { Antimycobacterials }\end{array}$ & $\begin{array}{c}\text { Increased residence time, increased macrophage uptake and } \\
\text { lymphatic system delivery achieved, decreased administration } \\
\text { frequency due to increased bioavailability [153, 168] }\end{array}$ \\
\hline
\end{tabular}

\subsection{Micelles}

Amphiphilic macromolecules having hydrophobic and hydrophilic regions have a tendency to assemble in aqueous environments at a concentration greater than the critical micellar concentration into nano-sized micelles. These have widespread application within pharmaceutics, as hydrophobic drugs can be encapsulated within the hydrophobic core of the micelles, allowing formulation at concentrations greater than their intrinsic water solubility. Moreover, the micelle can provide protection from degradation of the drug molecules and release kinetics can be manipulated by chemical alterations of the micelle surface, e.g. by cross-linking. Micelles can be formed from polymers/lipids that have been synthesized to achieve specific functionalities, such as targeting [156]. Polymeric micelles have been shown to be more stable than conventional surfactant micelles, having critical micellar concentrations less than $10^{-6} \mathrm{M}[156,169-171]$. One of the most prominent reasons for resistance to current antibiotics is the downregulation of uptake receptors on the surface of microorganisms. It would be an attractive approach to encapsulate such antibiotics within self-assembling micelles which would not be recognized by the receptor surfaces and hence help in intake of antibiotics into resistant bacteria. Micellar formulations encapsulating anti-microbial agents described in the literature are summarized in Table 7. 
Table 7: Nanomicelles in literature for delivery of antimicrobials for treatment of pulmonary infections.

\begin{tabular}{|c|c|c|c|}
\hline POLYMER/LIPID & ANTIMICROBIAL & MICROORGANISM & ADVANTAGES \\
\hline $\begin{array}{c}\text { Depolymerized chitosan- } \\
\text { stearic acid }\end{array}$ & Amphotericin B & $\begin{array}{c}\text { Candida albicans, Aspergillus } \\
\text { niger, Aspergillus fumigatus, } \\
\text { Aspergillus flavus Cryptococcus } \\
\text { neoformans }\end{array}$ & $\begin{array}{l}\text { Similar efficacy against all the different fungi } \\
\text { Retention of encapsulation of amphotericin B after } \\
\text { nebulization indicating no effect on the physical } \\
\text { properties of the micelles using a jet nebulizer [172] }\end{array}$ \\
\hline $\begin{array}{c}\text { Branched } \\
\text { polyethyleneimine-Stearic } \\
\text { acid lipopolymer }\end{array}$ & Antifungal & Mycobacterium smegmatis & $\begin{array}{l}\text { Higher uptake and internalization of the cationic } \\
\text { nanomicelles encapsulating rifampicin into phagosomal } \\
\text { compartments of the alveolar macrophage cells THP-1 } \\
\text { due to proton-sponge effect was observed [173] }\end{array}$ \\
\hline
\end{tabular}

\subsection{Large porous carriers}

Large porous carriers, referred to as 'Trojan particles' by Tsapi et.al [174] are newly engineered micrometer-sized particles for inhaled drug delivery. These can be of two types namely:

\section{Large porous particles (LPPs):}

These are characterized by a geometric size greater than 4 to $5 \mu \mathrm{m}$ and mass density less than $0.1 \mathrm{~g} / \mathrm{cm}^{3}$, resulting in in formation of particles which have a small aerodynamic diameter [42, 174, 175]. These are attractive system for pulmonary delivery as they have superior aerodynamic properties as compared to conventional particles of the same physical size. $60 \%$ of the nominal dose of such particles may reach the deep lung, and they are not cleared easily by alveolar macrophages, due to their large size. Hence they are attractive for sustained release of drug in the lungs [42, 176]. The highly porous surfaces and relatively large sizes of such particles help to decrease their surface energy, compared to conventional particle approaches, and hence inter-particulate cohesion is reduced and they disperse more easily in presence of airflow shear forces [42, 176]. This dispersion has low inter-patient variability, as it is independent of patients' peak inspiratory flow [42].

Large porous capreomycin particles were manufactured by spray drying with L-leucine from a $50 \%$ aqueous ethanol solution to produce particles having mass median aerodynamic diameter (MMAD) of $5 \mu \mathrm{m}$. Insufflations delivery of these particles to guinea pigs resulted in reduced bacterial burdens, decreased alveolar clearance and hence a potential to lower the dose and decrease toxic side effects [177]. Edwards et.al [178] determined the systemic bioavailability of insulin and suppression of blood glucose levels, using large porous PLGA particles encapsulating insulin, prepared by solvent evaporation techniques. Inhalation of large porous insulin particles (mean physical diameter $6.8 \mu \mathrm{m}$, MMAD $2.15 \mu \mathrm{m}$ ) demonstrated higher insulin bioavailaibity and glucose suppression for $96 \mathrm{~h}$ than non-porous insulin particles (mean diameter $4.4 \mu \mathrm{m}$, MMAD $2.15 \mu \mathrm{m}$ ) which showed lower bioavailabity and glucose suppression for only $4 \mathrm{~h}$. These results were attributed to the reduction in phagocytosis by deep lung alveolar macrophages, which are inefficient in removal of particles greater than $3 \mu \mathrm{m}$, leading to sustained release and greater bioavailability of insulin systemically [178].

An established engineering technique for preparation of LPPs is the Novartis PulmoSphere ${ }^{\mathrm{TM}}$ Technology. These are manufactured by emulsion-based spray-drying, wherein submicron oil in water emulsion droplets are generated by high pressure homogenization of perfluorooctyl bromide in water. The principal lipid component of PulmoSpheres is distearoylphosphatidylcholine (DSPC). Drugs, such as tobramycin and amphotericin B are dissolved in the water phase of the emulsion [42].

PulmoSphere formulations of anti-infectives, namely tobramycin, amphotericin B and ciprofloxacin have undergone at least Phase II clinical trials II. Tobramycin inhalation powder- TIPTM $\left(\mathrm{TOBI}^{\circledR}\right.$ Podhaler $^{\circledR}$; Novartis Pharmaceuticals) is safe and efficacious in treating $P$. aeruginosa lung infections in CF patients, and has now been licensed and is marketed in several European countries, South America and Canada [42], [43]. A questionnaire survey of 39 patients and their parents, as well as 54 respiratory therapists, revealed that $\mathrm{TIP}^{\mathrm{TM}} \quad\left(\mathrm{TOBI}^{\circledR}\right.$ Podhaler ${ }^{\circledR}$ ) was considered to be more convenient and acceptable than tobramycin inhalation solution (TIS ${ }^{\text {TM }}$ TOBI@) [42, 179]. Ciprofloxacin PulmoSpheres (Bayer HealthCare) have also shown efficacy for the treatment of $P$. aeruginosa in CF patients. Ciprofloxacin DPI was well tolerated in patients with minimal ciprofloxacin systemic adverse effects. $40 \%$ of the total dose was shown to reach the trachea/bronchi and alveolar space of the lungs, with the aim of increasing ciprofloxacin retention in the lung [180]. This formulation was successful in Phase I clinical trials in 2013 to evaluate the potential of ciprofloxacin DPI for mild to moderate COPD. It also passed Phase II studies to evaluate safety and efficacy in patients with CF in May 2014 [47, $181,182]$.

Large porous nanoparticle aggregates (LPNAPs):

LPNAPs comprise micron-sized particles consisting of nanoparticles (1-100 nm) held together by van der Waals 
forces or present in matrix having components such as biopolymers, surfactants, amino acids, lipids and proteins. LPNAPs have been made from a range of materials including silica, polystyrene, DPPC, albumin, hydroxypropyl cellulose, lactose etc. in sizes ranging from 25 to $1000 \mathrm{~nm}$. LPNAPs have similar physical and aerodynamic properties to LPPs, and once delivered to the lungs they dissociate to form individual nanoparticles [174]. LPNAPS can overcome the problems associated with pulmonary delivery of nanoparticles, i.e. exhalation due to their small size, yet provide the advantages of nanoparticles when they are liberated in situ following deposition of the larger particles in the lungs.

\section{ADVANTAGES OF NANO-ANTIMICROBIALS}

\subsection{Protective vesicles preventing antimicrobial degradation}

Nanocarriers can be an attractive approach for delivery of antimicrobials as they provide a protective environment that shields the antibiotic preventing degradation. Antibiotic inactivation by enzymes or interactions with other components in the biofilm matrix may reduce drug activity or cause complete resistance to it.

Mugabe et.al [183] have demonstrated that gentamicin encapsulated in liposomes showed superior activity than drug alone for eradication of resistant strains of $P$. aeruginosa isolated from clinical $\mathrm{CF}$ patients. Three different liposomal formulations: DPPC:Chol, DMPC:Chol and DSPC:Chol encapsulating gentamicin showed significantly higher antimicrobial activity than drug alone and enhanced the susceptibility of $P$. aeruginosa from highly resistant to gentamicin (MIC>16 $\mathrm{mg} / \mathrm{L}$ ) to either intermediate $(\mathrm{MIC} \leq 8 \mathrm{mg} / \mathrm{L})$ or highly susceptible (MIC $\leq 4$ $\mathrm{mg} / \mathrm{L}$ ) for the non-mucoid and mucoid strains of Pseudomonas respectively. The mechanism of enhanced activity due to the protection of the drug against enzymatic degradation, and ease of diffusion across the bacterial envelope [183, 184].

Turos et.al [185] evaluated the activity of penicillin encapsulated within polyacrylate nanoparticles, prepared by free radical emulsion polymerization, against resistant strains of S.aureus. Microbiological assays indicated that the antimicrobial properties of nanoparticle-encapsulated penicillin were retained, whilst free penicillin completely lost activity in the presence of penicillinase [184-186].

$\mathrm{CF}$ sputum being rich in polyanionic components, namely mucin, DNA, F-actin, lipopolysaccharides and lipoteichoic acid has been shown to reduce the antimicrobial properties of the cationic antibiotics polymyxin and tobramycin, due to formation of an electrostatic-attraction complex, hampering complete eradication of the bacteria [99, 187, 188]. Encapsulation of these antibiotics in liposomes reduces formation of the electrostatic complex 100-fold, giving a 4fold improved inhibition of $P$. aeruginosa colonies, suggesting a potential application in eradication of chronic lung infections associated with CF [184, 187].
Co-encapsulation of antimicrobial substances, such as metals with antibiotics in liposomes not only reduces the toxicity issues associated with metals on human cells but has also improved the activity of the co-encapsulated antibiotic [184, 189-194]. Halwani et.al [189] studied the effect of coencapsulating of bismuth-ethanedithiol and tobramycin (BiEDT-TOB) in DSPC:Chol liposomes on highly resistant strains of $P$. aeruginosa PA-48913. MIC values for liposomal BiEDT-TOB were $0.25 \mathrm{mg} / \mathrm{L}$ compared to 1024 $\mathrm{mg} / \mathrm{L}$ for non-liposomal drug, which could serve as a new strategy for enhancing the antibacterial properties of tobramycin against resistant bacteria [189]. Halwani et.al [190] have also reported the activity of DPPC:DMPG coencapsulated gallium with gentamicin (Ga-GEN) liposomes against highly resistant strains of $P$. aeruginosa $P A-48913$. Liposomal Ga-GEN formulations completely eradicated the bacterial isolates growing in planktonic and biofilm communities at a concentration as low as $0.94 \mathrm{mg} / \mathrm{L}$. They also interfered with the release of virulent factors, alginate and biofilm [184, 190, 192].

\subsection{Controlled release}

Antimicrobial therapy is hampered by the short availability of drug at the target site, potentially limiting treatment outcomes. Currently for chronic pulmonary infections, highdoses and frequent parenteral administration are necessary to achieve the pulmonary sputum concentrations required to eradicate the chronic colonies of biofilm-associated bacteria [195-197]. However, protracted and recurrent administration of high dose antibiotics is associated with antibiotic resistance [197-199]. Inhaled antibiotics also face considerable challenges as they are rapidly cleared from the lungs by natural clearance mechanisms, namely exhalation for small particles, phagocytosis by macrophage and dendritic cells, mucociliary clearance, enzyme degradation etc. This may lead to antibiotic exposure at sub-inhibitory levels, leading to incomplete eradication of bacterial colonies embedded in the protective layers of sputum and biofilms, leading to higher incidences of antibiotic resistance [98].

A logical approach to enhance the delivery of antibiotics for treating chronic infections, by increasing their residence time, is to load them into appropriately sized carriers which could serve to deliver the drug to the site of infection. However, chronic administration of the carrier may lead to their accumulation in the airways. Despite the phospholipids used in the preparation of liposomes sometimes being endogenous to the lungs; their repeated administration can lead to cumulative doses of lipids in the lungs greater than the original surfactant pool, resulting in adverse effects, such as phospholipidosis [130, 200, 201]. Hence, excipients should be minimised, with nanocarriers designed to deliver antimicrobials encapsulated in controlled/sustained/extended release vesicles which release drug over extended periods, maintaining therapeutic levels in the vicinity of the biofilm, improving patient compliance whilst reducing chances for development of resistance $[98,197]$.

Although a number of research articles have been published on the controlled release of antibiotics given systemically or as post-operative implants, few reports are associated with controlled release of antibiotics following pulmonary 
delivery [130, 202-204]. One such study used the encapsulation of nafcillin and levofloxacin in PLGA nanoparticles coated with calcium phosphate, to achieve controlled release of the antibiotics. The nanoparticles showed sustained release for 4-6 weeks and inhibited biofilm formation with complete deterioration of S.aureus biofilms over a 7 day period [205].

Another study demonstrated the anti-microbial property of gentamicin encapsulated in PLGA nanoparticles. In-vitro efficacy of the PLGA encapsulated gentamicin against $P$. aeruginosa biofilm was superior to free drug, due to achievement of a sustained level of gentamicin in the biofilm. Moreover, peritoneal injection in murine infection models showed the effective clearance of bacteria and an enhanced anti-biofilm effect by PLGA encapsulated gentamicin after $96 \mathrm{~h}$, compared to free gentamicin. Empty PLGA nanoparticles did not demonstrate any antimicrobial effect against $P$. aeruginosa $[184,206]$.

Cheow and co-workers have illustrated the importance of antibiotic release profiles on the anti-bacterial activity against biofilm-associated E.coli. Two nanoparticle systems: an extended (slow) release and a biphasic system with an initial burst release and subsequent slow release, encapsulating the hydrophilic antibiotic levofloxacin were prepared, using either poly(caprolactone) (PCL) or PLGA polymers. Nanoparticles were prepared using two different methods, namely nanoprecipitation and emulsificationsolvent evaporation. It was observed that with the extendedrelease nanoparticles encapsulating levofloxacin, the concentration of antibiotic was above the MBIC value at all times, but was unsuccessful in eradicating biofilm-associated bacterial cells. A higher antibiotic resistance was prevalent in the biofilm cells with lower initial antibiotic concentration, which was then passed onto the progeny leading to ineffective eradication. For the biphasic-release nanoparticulate system was better in decelerating occurrence of biofilm formation, indicating the importance of a high initial local concentration, then an extended release to maintain the concentration of drug in the biofilm above the MBIC at all times. However, over a 6-day period both nanoparticulate antibiotic preparations were unable to prevent biofilm growth when a single dose was administered. Nevertheless a related study by the same group demonstrated the effect of release profile of hydrophobic ciprofloxacin encapsulated in PLGA and PCL nanoparticles, prepared by the emulsion-solvent evaporation method. PLGA encapsulated ciprofloxacin, over a 5-day period, showed successful inhibition of the biofilm- associated bacteria even at concentration as low as $1 / 16^{\text {th }}$ of the MBIC, indicating this to be a highly effective formulation for eradication of biofilm-associated E.coli. [184, 207-209]. These studies highlight in considering the susceptibility of chronic bacterial infections to nanocarrier formulations of antimicrobials, the importance of the formulation parameters, such as drug properties, choice of polymer, method of preparation of nanoparticles, release profile, etc.

\subsection{Non-specific targeting}

Nanoparticles can be targeted passively by selective extravasation at the site of infection, due to the increased porosity of blood vessel induced by increased inflammatory factors [53]. Eradication of intracellular organisms presents severe challenges as therapeutic concentrations of antimicrobials in intracellular compartments are difficult to achieve due to their limited penetration capacity [210, 211]. Thus, many antibiotics, such as $\beta$-lactam and aminoglycoside antibiotics show low concentrations in intracellular compartments due to poor penetration and acidic and enzymatic degradation. However, water-soluble quinolone and macrolide antibiotics, such as clindamycin, levofloxacin, etc. attain higher intracellular concentrations as opposed to extracellular concentrations [210-212]. Mycobacterium tuberculosis binds to and internalizes in the alveolar macrophages as a survival mechanism, and hence is very difficult to eradicate completely. A study of liposomeencapsulated clofazimine against TB showed that liposomal formulations were much more effective in being taken up naturally by the macrophages, where the infection prevails, improving treatment outcomes and reducing off-target toxicity of the anti-tubercular drug in-vitro and in-vivo [213, 214]. Liposomal clofazimine was more effective in treatment of acute and chronic murine TB, giving a bactericidal effect with no re-emergence of Mycobacterium tuberculosis infection in mice [213, 214]. Another study by Stoops et al showed that lipids have the tendency to strip off the waxy trehalose dimycolate armour of Mycobacterium making it more susceptible to anti-tubercular drugs hence improving their efficacy [215].

The fusogenic property of liposomes makes them an attractive approach for delivering antibiotics directly to cells, due to their potential to fuse with phospholipid cell membranes. The fluidity of the liposomes can be achieved by lowering the phase transition temperature, by incorporation of components of the inactivated Sendai virus envelope, using lipids which have the phosphatidylethanolamine moiety, lipids with double bonds and/or asymmetry in acyl chain, or by addition of cholesterol [184, 216-220]. Antibiotics enter Gram-negative bacteria by two routes: hydrophobic drugs enter by passive transport via the lipopolysaccharide and protein-rich outer membrane; whereas hydrophilic drugs enter through the outer membrane water-filled porin channels. A reduction in antibiotic susceptibility of resistant strains of bacteria has been reported due to acquisition of genetic factors which lead to changes in the bacterial outer membrane porin channels, which strongly impacts the influx of antibiotics and hence bacterial susceptibility [219, 221-224]. Nicolosi et al. have studied the antimicrobial sensitivity of the glycopeptide antibiotic vancomycin against ten wild strains of Gramnegative bacteria using vancomycin encapsulated in fusogenic: (DPPC:DOPE:cholesterol hemisuccinate) and non-fusogenic liposomes (DPPC: cholesterol) as well as free drug. A significant reduction in MIC was observed for the vancomycin encapsulated in fusogenic liposomes for all the strains of bacteria tested, with an MIC as low as $6 \mathrm{mg} / \mathrm{L}$ for strains of E.coli and Acinetobacter baumannii, compared to vancomycin encapsulated non-fusogenic liposomes and free vancomycin which both had an MIC of $512 \mathrm{mg} / \mathrm{L}$. This was due to the fusogenic phospholipid vesicles fusing with the 
E.coli bacterial membrane, as confirmed by scanning and transmission electron micrographs $[219,225]$.

Beaulac et al. showed that bacterial susceptibility to antibiotics encapsulated in liposomes is largely determined by the fluidity of the liposomal phospholipid bilayer. In vivo studies were performed on the lungs of rats which were chronically infected intratracheally with the mucoid variant of Pseudomonas aeruginosa (PA 508), which is the most common opportunistic organism accelerating chronic pulmonary infection in cystic fibrosis patients, and in noncystic fibrosis bronchiectasis patients. A significantly improved antimicrobial susceptibility was evidenced by a dramatic reduction in mucoid bacterial load in the lungs (0-8 $\mathrm{CFU} /$ pair of lungs) for the tobramycin encapsulated in DPPC: DMPG liposomes called Fluidosomes ${ }^{\mathrm{TM}}$ which had a phase transition temperature $(\mathrm{Tc})$ of $29.5^{\circ} \mathrm{C}$. Free tobramycin and tobramycin encapsulated in rigid DSPC: DMPC liposomes $\left(\mathrm{Tc}=42^{\circ} \mathrm{C}\right)$ showed much higher bacterial loads of $2 \times 10^{5}-4.2 \times 10^{7}$ and $1.9 \times 10^{5}-4.3 \times 10^{6} \mathrm{CFU} /$ pair of lungs respectively, with three doses of $600 \mu \mathrm{g}$ at $16 \mathrm{~h}$ intervals. Moreover, distribution studies after the last treatment of the liposomal formulation and the free antibiotic showed a high level $\geq 27 \mu \mathrm{g} / \mathrm{mg}$ in lung tissue, and $0.59-0.87 \mu \mathrm{g} / \mathrm{mg}$ of tissue detected in the kidneys as opposed to $5.31 \mu \mathrm{g} / \mathrm{mg}$ of kidney tissue for the free drug. This suggests that liposome encapsulated tobramycin would not only be beneficial for management of chronic pulmonary infection, but also in reducing the systemic side effects and toxicity associated with conventional antibiotics. Moreover, studies performed with the DPPC: DMPG liposomes $\left(\mathrm{Tc}=33^{\circ} \mathrm{C}\right)$ at a lower dose regimen of two tobramycin treatments of $240 \mu \mathrm{g}$ at $16 \mathrm{~h}$ intervals showed a bacterial load of. 0-3 CFU/pair of lungs comparable with the high-dose treatments, whereas free tobramycin showed a significantly higher bacterial load of $1.6 \times 10^{5}-1.5 \times 10^{6} \mathrm{CFU} /$ pair of lungs $[184,226]$.

Fluidosomes ${ }^{\mathrm{TM}}$-Tobramycin is being developed by Axentis Pharma (Switzerland) and has shown good safety and efficacy profiles in pre-clinical and Phase II clinical trials when compared to the present available marketed treatments for management of chronic infection caused by Burkholderia cepacia pathogens associated with cystic fibrosis.

Non-specific approaches to targeting suffer from the drawbacks of non-specific drug delivery and uptake, hence selectively targeting to the site of infection may represent an attractive approach to increase uptake, to achieve higher doses to eradicate bacteria at the appropriate site, allow a reduction in dose and potentially reduce the potential for antimicrobial resistance.

\subsection{Specific targeting}

7.4.1 Biofilm targeting- Understanding the generation of biofilms at the genetic and molecular levels has informed the development of drug delivery systems which may help in overcoming this physical barrier to effective antimicrobial therapy, and help in better elimination of chronic bacterial infections associated with biofilms.

$\mathrm{Li}$ et al. demonstrated the influence of nanoparticle surface properties with respect to both surface charge and hydrophobicity/hydrophilicity on the penetration of biofilms secreted by E. coli strain DH5a. Quantum dots (QD) with different functional head groups were synthesized by surface modification to obtain neutral, i.e. poly(ethylene glycol)appended DHLA-QD, negatively-charged $\mathrm{COOH}-\mathrm{QD}$ and positively-charged QD which were further designed to be hydrophobic, i.e. dimethylhexyl ammonium terminus (Hexyl-QD) or hydrophilic i.e. trimethylammonium terminus (TTMA-QD). 3-D projection of images obtained from a zstack using a confocal laser scanning microscope clearly showed that the neutral (PEG-QD) and negative-charged COOH-QD did not adhere or penetrate into the EPS of the biofilm, demonstrated by the absence of green fluorescence indicative of the QD amidst the red, fluorescing bacterial cells. Both the hydrophobic and hydrophilic positivelycharged QDs showed a high intensity of green fluorescence which did not disappear on washing the biofilms with PBS, whilst quantification of penetration profiles of the positively charged QDs showed they had travelled through the biofilm to a depth of $7.2 \mu \mathrm{m}$. Moreover, co-localization of the hydrophobic Hexyl-QDs with the bacterial cells indicated greater uptake of these compared to the hydrophilic TTMAQDs which primarily localized in the EPS of the biofilm. Hence this study has shown the importance of charge and surface properties, whereby a hydrophobic surface of nanoparticles could be engineered to deliver antibiotics for eradication of chronic intracellular pathogens, whereas a hydrophilic surface modification could serve to target enzymes and other biofilm-dissolving drugs, for dispersion of biofilms [227].

An attractive approach in disassembling the EPS matrix of bacterial biofilms, and hence enhancing antibiotic therapy was studied by Baelo et al. Ciprofloxacin was loaded into PLGA nanoparticles, with and without a coating of DNAse enzyme. This enzyme has been found to be very effective in disrupting the integrity and viscoelastic nature of the DNArich EPS of biofilms, and greatly improves diffusion through it $[228,229]$. Ciprofloxacin was encapsulated in PLGA coated with DNAse by means of covalent linkage using poly-lysine on the surface of PLGA nanoparticles. These particles had improved mobility in Pseudomonas aeruginosa biofilms in both static and dynamic conditions, providing a platform for treatment of biofilm-associated bacteria with biofilm disassembling and anti-bacterial agents [229].

7.4.2 Sputum targeting- The CFTR gene defect discovered in 1989 has not yet resulted in a cure for CF. Major treatment failures have been attributed to the hyper-viscoelastic mucus 'sputum' due to inefficient transport of therapeutics. This pathological complication also affects treatment of other etiological diseases, such as COPD, chronic bronchiectasis and asthma. Numerous studies have been conducted on the sputum expectorated from CF patients to understand the nature of the matrix microstructure, mesh spacing and its components to aid in delivering antibiotics and gene vectors through this obstacle. Suk et al. have shown that densely packed low molecular weight PEG imparted 'mucoinertness' to the surface of polystyrene (PS) nanoparticles of different sizes. Transport of these nanoparticles through CF sputum, studied using multiple particle-tracking analysis, showed that the uncoated PS nanoparticles with a charge on the surface due to a terminal amine group had a strongly 
hindered transport, whereas similarly sized nanoparticles with a muco-inert surface which showed greater movement in time-lapse studies. This was attributed to possible polyvalent adhesion interactions between the hydrophobic mucin fibres and hydrophobic core of PS nanoparticles, and also electrostatic interactions of the positively-charged nanoparticles with sputum components, such as DNA, Factin etc. all of which were masked when particles were densely coated with hydrophilic, uncharged PEG molecules [229]. A further study has been conducted by the same group, in which the transport of biodegradable, di-block copolymers prepared from sebacic acid and methoxy-PEG were compared to latex particles in undiluted sputum expectorated from $\mathrm{CF}$ patients. It was seen that the biodegradable muco-inert nanoparticles had a mean square displacement 50-fold greater compared to uncoated latex particles, and a Fick diffusion model confirmed the penetration of the muco-inert PSA-PEG nanoparticles to be $31 \%$ in 30 mins compared to the unmodified particles which showed strong immobilization and penetration of only $0.6 \%$ in CF sputum [230]. These studies demonstrate the importance of nanoparticle properties such as surface charge, hydrophobicity, molecular weight, size, etc. on the transport of particles and the encapsulated drug through the sputum $[229,230]$.

7.4.3 Macrophage targeting- As highlighted above, alveolar macrophages play a major role in combating infections. However in chronic infections, bacteria and other organisms take these over, locating themselves in the protective environment where they multiply and become difficult to eradicate with routine antibiotics. To eradicate these intracellular infections, directly targeting to the macrophages could be a highly effective strategy. Much research has been performed to study the potential of PLGA microparticles and nanoparticles to target the alveolar macrophages, as they may remain membrane bound onto the alveolar macrophages for up to 2 weeks [231-239]. Makino et al. showed the phagocytic uptake of rifampicin encapsulated in PLGA nanoparticles. 19-times higher uptake of rifampicin by the macrophage cells in-vitro was found for PLGA-encapsulated rifampicin formulation compared to free drug in solution [236]. A similar study exploring the reasons for an increased uptake of PLGA nanoparticles into macrophage cells, concluded that $90 \%$ of PLGA nanoparticles encapsulating rifampicin were taken up and remained membrane bound onto the low $\mathrm{pH}$ hydrolase rich regions of the phagolysosomes for 13 days, as shown by fluorescence and immune-electron microscopy, from where rifampicin is released over time. Further studies have confirmed that this formulation system was more efficient in eradication of mycobacterium bovis infected macrophage RAW cells compared to free rifampicin at the same concentration. Actively targeting nanoparticles to alveolar macrophages has been extensively investigated for treatment of various infections associated with tuberculosis, visceral leishmaniasis, arthritis, etc. [240-242]. Gelatin nanoparticles encapsulating isoniazid with and without mannose conjugated to the surface of nanoparticles, required for selective delivery to macrophages, have been studied.
Macrophage-uptake studies showed that mannosylated nanoparticles were taken up preferentially into macrophages compared to non-mannosylated nanoparticles. The antitubercular activity, studied by inducing $\mathrm{TB}$ infection in $\mathrm{BALB} / \mathrm{C}$ mice, showed much lower $\mathrm{CFU} / \mathrm{ml}$ of spleen when the mice were treated with mannosylated gelatin nanoparticles encapsulating isoniazid, compared to nonmannosylated nanoparticles encapsulating isoniazid and free isoniazid. This suggests the macrophage uptake of the drug encapsulated in nanoparticles is an important pre-requisite for treatment of intracellular infections. Similar results have been observed by others, studying conjugation of mannose onto SLNs, polypropyleneimine dendrimers, etc [243-245].

Higher uptake and retention in lung tissue- Antimicrobial lung concentrations are of crucial importance, as a drug concentration above the MIC and MBIC are required to achieve successful eradication of the infecting pathogens. Liposome-encapsulated amphotericin B has been long been successfully marketed under the name AmBisome for intravenous infusion for the treatment of severe systemic and deep mycosis in the lungs. Several studies have been performed delivering these liposomes and other lipid-based systems via nebulization directly to the pulmonary tract to achieve high local concentrations and reduce undesirable systemic effects [246-248]. One such study has highlighted the beneficial effects of nebulized amphotericin B encapsulated in liposomes, compared to Fungizone (sodium deoxycholate complex) using a SPAG-2 nebulizer. AmBisome showed an eight-time higher concentration in the lungs $(207 \mu \mathrm{g} / \mathrm{mg}$ lung tissue) than Fungizone $(24.4 \mu \mathrm{g} / \mathrm{mg}$ lung tissue) using in-vivo in murine models infected with Aspergillus fumigatus. Also, with a medium infection load of $10^{7} \mathrm{CFU} / \mathrm{g}$ of tissue, AmBisome produced nearly completely eradicate from the lungs (mean CFU/g of lung tissue $=0.54$ ); however, Fungizone showed no improvement in eradication compared to the control group (mean CFU/g of lung tissue $=3.31$ for Fungizone and 5.30 for control). This demonstrates the importance of higher lung retention achieved with nanotechnology- based vesicles and their consequent beneficial effects on eradication of bacteria. Clinical trials are on-going for nebulized AmBisome (AMBINEB) in prophylaxis of Invasive Pulmonary Aspergillosis in patients with Acute Myeloid Leukaemia and Allogeneic Haematopoietic Progenitor Cell Transplantation. Further clinical trials are being conducted following completion of Phase II studies of prophylactic nebulization of amphotericin B-lipid complex (Albecet ${ }^{\circledR}$ ) in paediatric patients with acute leukaemia [246-248].

\section{DISADVANTAGES OF NANO-ANTIMICROBIALS}

8.1 Formulation drawbacks: Nanoparticles present many challenges, potentially limiting their progress onto the market. Key drawbacks are (1) Scale up and transitional development from the laboratory bench to industrial production is a challenge due to differences in the properties of nanoparticles compared to their bulk counterparts. Smaller sizes and commensurate large surface area can lead to high chances of aggregation, hindering physical handling at an industrial level [249]. (2) Low drug encapsulation is a major 
limitation, and is often dependent on aqueous/lipid solubility, as exemplified by a drug's $\log$ P. (3) Stability of nanocarrier-drug formulation may be problematic, for instance leakage of drug on storage, changes in size and surface properties and, particle-particle interaction and aggregation (4) Stability of formulation to aerosolization processes, especially by nebulization of nanocarriers dispersed in liquid, which may result in particle rupture and drug loss and consequently unpredictable deposition patterns within the airways.

8.2 Toxicity of nanoparticles to the lung: With the advent of nanoparticle drug delivery in pharmaceutical, biomedicine and cosmeceutical areas, the field of nanotoxicology has emerged to investigate potential adverse reaction to nanoparticles [53, 250]. Nanomaterial structures, due to their very small size and large surface area have a potential to be more toxic than conventionally sized bulk samples of the same materials. This is due to their deeper lung penetrations, large surface/mass ratios, aggregation capabilities and low water solubility. It has been seen that human alveolar macrophages are not capable of removing nanoparticles of size $70 \mathrm{~nm}$ and less, leading to their deep lung access and entrance into bloodstream through the alveolar epithelium, and causing evident inflammation in other organs. The aggregation state is another important determinant. Aggregates of ultrafine carbon particles at concentrations of $1 \mu \mathrm{g} / \mathrm{ml}$ and greater impair the phagocytic function of human alveolar macrophage. The large surface area/mass ratio enables these nanoparticles to undergo various reactions which result in toxicity and cause inflammation in animal models, whereas their counterpart larger particles have demonstrable safety. This is due to novel surface characteristics which may contribute to reactions like generation of reactive oxygen species, i.e. free radical formation as shown for $\mathrm{CuO}$ and $\mathrm{SiO} 2$ nanoparticles; interlukin-8 cytokine production evident following exposure to cobalt or $\mathrm{TiO} 2$ nanoparticles; increase in mRNA levels of inflammatory markers shown for by yttrium and zinc oxide nanoparticles.

To study toxicity, regulatory authorities require animal studies; however, in-vivo studies are conducted using oral, intraperitoneal or dermal routes which do not completely portray inhalation effects. In-vitro methods have been developed to study toxic effects on airway cells (Calu-3 human cell line), alveolar epithelium (A549-human cell line) or tissues. These are quicker, simpler and less expensive than in-vivo tests. However, they do not completely take in account lung characteristics, such as microenvironments and inhalation effects.[250].

\section{CONCLUSION}

Huge research efforts are being made to overcome the drawbacks of conventional antimicrobials used to treat lower respiratory tract infections, which are one of the leading causes of death worldwide. In light of the increased incidence of multidrug resistance to conventional antimicrobials, there is an urgent need for better treatment modalities. Moreover, the high rates of side effects with prolonged oral and parenteral delivery of current antimicrobials and low drug availability at the pulmonary site leads to insufficient levels of drug in the sputum for eradication of infections. This is one of the greatest reasons for failure of current treatments for pulmonary infections. Direct delivery of antimicrobials, by inhalation, to the pulmonary tract could help in not only reducing side effects, but also in lowering the dose required to eradicate the bacterial load and reduce the potential for resistance and recurrence of infection. Furthermore, targeting therapeutic agents to the intracellular pathogens, or to pathogens embedded within protective coverings like sputum and biofilms, may be achieved by utilizing one of the ever-growing nanotechnology platforms for encapsulation of antimicrobials into nanosized vesicles, such as liposomes, polymeric nanoparticles or micelles. Development of nanosized drug delivery systems encapsulating antimicrobial drugs capable of being directly administered to the lungs could result in breakthroughs in the therapy of notoriously difficult to treat pulmonary infections.

\section{CONFLICT OF INTEREST}

The authors declare there are no conflicts of interest

\section{LIST OF ABBREVIATIONS}

$\begin{array}{ll}\text { BAL } & \text { Broncho-alveolar lavage } \\ \text { CAP } & \text { Community acquired pneumonia } \\ \text { CB } & \text { Chronic bronchitis } \\ \text { CF } & \text { Cystic fibrosis } \\ \text { CFU } & \text { Colony forming units } \\ \text { CHOL } & \text { Cholesterol } \\ \text { COPD } & \text { Chronic obstructive pulmonary disease } \\ \text { DCP } & \text { Dicetyl phosphate } \\ \text { DMPC } & \text { 1,2-dimyristoyl-sn-glycero-3-phosphocholine } \\ \text { DMPG } & \text { 1,2-Dimyristoyl-sn-glycero-3-phosphoglycerol } \\ \text { DOPE } & \text { 1,2-Dioleoyl-sn-Glycero-3-Phosphoethanolamine } \\ \text { DPPC } & 1,2 \text {-dipalmitoyl-sn-glycero-3-phosphocholine } \\ \text { DPI } & \text { Dry powder inhaler } \\ \text { DSPC } & 1,2 \text {-dioctadecanoyl-sn-glycero-3-phosphocholine } \\ \text { DSPG } & \text { 1,2-Distearoyl-sn-glycero-3-phosphoglycerol } \\ \text { EGG PC } & \text { Egg phosphatidylcholine } \\ \text { EPS } & \text { Extracellular polymeric substance } \\ \text { GSD } & \text { Geometric standard deviation } \\ \text { HLB } & \text { Hydrophilic-lipophilic balance } \\ \text { HSPC } & \text { Hydrogenated soybean phosphatidylcholine } \\ \text { LPNAPS } & \text { Large porous nanoparticle aggregates } \\ \text { LPP } & \text { Large porous particle } \\ \text { MAN } & \text { Mannose } \\ \text { MBIC } & \text { Minimum biofilm inhibitory concentration } \\ \text { MDR-TB } & \text { Multi-drug resistant tuberculosis } \\ \text { MIC } & \text { Minimum inhibitory concentration } \\ \text { MMAD } & \text { Mass median aerodynamic diameter } \\ \text { PCL } & \text { Poly-epsilon-caprolactone } \\ \text { PLGA } & \text { Poly(lactic-co-glycolic acid) } \\ \text { pMDI } & \text { Pressurized metered dose inhaler } \\ \text { QD } & \text { Quantum dot } \\ \text { TB } & \text { Tuberculosis } \\ \text { TDR-TB } & \text { Totally drug resistant } \\ \text { VAP } & \text { Ventilator-associated pneumonia } \\ \text { XDR-TB } & \text { Extensively drug resistant } \\ & \end{array}$




\section{REFERENCES}

[1] Sanders M. Pulmonary Drug Delivery: An Historical Overview. In: Smyth HDC, Hickey AJ, Eds. Controlled Pulmonary Drug Delivery. New York: Springer 2011; pp. 51-73.

[2] Garcia FD. Nanomedicine and therapy of lung diseases. Einstein (São Paulo) [Internet]. 2014 Dec [cited 2016 Mar 15]; 12( 4 ): 531-533. Available from:

http://www.scielo.br/scielo.php?script=sci_arttext\&p $\mathrm{id}=\mathrm{S} 1679-45082014000400531 \& \operatorname{lng}=\mathrm{en}$.

[3] Kwok PC, Chan HK. Pulmonary drug delivery. Ther Deliv. 2013, 4, 877-8.

[4] Sawaya B, Briggs J, Schnermann J. Amphotericin B nephrotoxicity: the adverse consequences of altered membrane properties. J Am Soc Nephrol 1995; 6(2): 154-64.

[5] Deray G. Amphotericin B nephrotoxicity. J Antimicrob Chemother. 2002; 49(1): 37-41.

[6] Laniado-Laborín R, Cabrales-Vargas MN. Amphotericin B: side effects and toxicity. Rev Iberoam Micol. 2009; 26(4): 223-7.

[7] Van Der Meulen J, De Jong GM, Westenend PJ. Acute interstitial nephritis during rifampicin therapy can be a paradoxical response: a case report. Cases $\mathbf{J}$ 2009; 2: 6643.

[8] Kumar BD, Prasad CE, Krishnaswamy K. Detection of rifampicin-induced nephrotoxicity by N-acetyl-3D-glucosaminidase activity. J Trop Med Hyg 1992; 95(6): 424-7.

[9] Agu RU, Ugwoke MI, Armand M, Kinget R, Verbeke N. The lung as a route for systemic delivery of therapeutic proteins and peptides. Respir Res 2001; 2(4): 198-209.

[10] Delmas G1, Park S, Chen ZW, Tan F, Kashiwazaki $\mathrm{R}$, Zarif L, et al. Efficacy of orally delivered cochleates containing amphotericin $\mathrm{B}$ in a murine model of aspergillosis. Antimicrob Agents Chemother 2002; 46(8): 2704-7.

[11] Amidon GL, Lennernäs H, Shah VP, Crison JR. A theoretical basis for a biopharmaceutic drug classification: the correlation of in vitro drug product dissolution and in vivo bioavailability. Pharm Res
1995; 12(3): 413-20.

[12] Gershkovich P, Wasan EK, Lin M, Sivak O, Leon CG, Clement JG, et al. Pharmacokinetics and biodistribution of amphotericin $\mathrm{B}$ in rats following oral administration in a novel lipid-based formulation. J Antimicrob Chemother 2009 Jul;64(1):101-8.

[13] Hussain M, Madl P, Khan A. Lung deposition predictions of airborne particles and the emergence of contemporary diseases, Part-I. The Health 2011; 2(2): 51-9.

[14] Dolovich MB, Dhand R. Aerosol drug delivery: developments in device design and clinical use. Lancet 2011; 377(9770): 1032-45.

[15] Stuart BO. Deposition and clearance of inhaled particles. Environ Health Perspect 1984; 55: 369 390.

[16] Hickey AJ, editor. Pharmaceutical inhalation aerosol technology, 2nd ed. New York: Marcel Dekker, Inc.

[17] Darquenne C, Prisk GK. Aerosol deposition in the human respiratory tract breathing air and 80:20 heliox. J Aerosol Med. 2004; 17(3): 278-285.

[18] Hassan MS, Lau RWM. Effect of particle shape on dry particle inhalation: study of flowability, aerosolization, and deposition properties. AAPS PharmSciTech. 2009; 10(4): 1252-1262.

[19] Russo P, Santoro A, Prota L, Stigliani M, Aquino RP. Development and investigation of dry powder inhalers for Cystic Fibrosis. In: Sezer AD. editor. Recent advances in novel drug carrier systems, InTech 2012; pp. 17-38.

[20] Hamishehkar H, Emami J, Najafabadi AR, Gilani K, Minaiyan M, Mahdavi $\mathrm{H}$, et al. Effect of carrier morphology and surface characteristics on the development of respirable PLGA microcapsules for sustained-release pulmonary delivery of insulin. Int $\mathbf{J}$ Pharm 2010;389(1-2):74-85.

[21] Kawashima Y, Serigano T, Hino T, Yamamoto H, Takeuchi H. Effect of surface morphology of carrier lactose on dry powder inhalation property of pranlukast hydrate. Int. J Pharm 1998; 172(1): 17988 . 
[22] Zeng XM, Martin GP, Marriott C, Pritchard J. The influence of carrier morphology on drug delivery by dry powder inhalers. Int J Pharm 2000; 200(1): 93106.

[23] Chan HK, Gonda I. Aerodynamic properties of elongated particles of cromoglycic acid. J Aerosol Sci 1989; 20(2): 157-68.

[24] Scheuch G, Heyder J. Dynamic shape factor of nonspherical aerosol particles in the diffusion regime. Aerosol Sci. Technol 1990; 12(2): 270-7.

[25] Ghilzai NK. Pulmonary drug delivery, 2008. Available from: http://www.drugdel.com/Pulm_review.pdf [accessed August 9,2013].

[26] Welch MJ, Smaldone GC. Effective use of nebulizer systems in pediatric asthma therapy. Adv Phys Assist 2002; 10: 52.

[27] Labiris NR, Dolovich MB. Pulmonary drug delivery. Part II: the role of inhalant delivery devices and drug formulations in therapeutic effectiveness of aerosolized medications. Br J Clin Pharmacol 2003; 56(6): 600-12.

[28] Bailey MM, Berkland CJ. Nanoparticle formulations in pulmonary drug delivery. Med Res Rev 2009 Jan; 29(1): 196-212.

[29] Patil JS, Sarasija S. Pulmonary drug delivery strategies: A concise, systematic review. Lung India. 2012; 29(1): 44-9.

[30] Yurteri CU, Hartman RPA, Marijnissen JCM. Producing pharmaceutical particles via electrospraying with an emphasis on nano and nano structured particles -- a review. Kona Powd Part J 2010; 28: 91-115.

[31] Chattopadhyay S, Modesto-Lopez LB, Venkataraman C, Biswas P. Size distribution and morphology of liposome aerosols generated by two methodologies. Aerosol Sci Technol 2010; 44(11): 972-82.

[32] Pilcer G, Amighi K. Formulation strategy and use of excipients in pulmonary drug delivery. Int $\mathbf{J}$ Pharm 2010; 392(1-2): 1-19.
Smith IJ, Parry-Billings M. The inhalers of the future? A review of dry powder devices on the market today. Pulm Pharmacol Ther 2003; 16(2): 79-95.

[34] Sumby B, Slater A, Atkins PJ, Prime D. Review of dry powder inhalers. Adv Drug Deliv Rev 1997; 26(1): 51-8.

[35] Ganderton D, Lee KC, Marriott C, Martin GP, Suen KO, Timsina M, Yianneskis $M$, inventor. Dry powder inhalers. WO Patent WO1995017917 A1, 1995 Jul.

[36] Minne A, Boireau H, Horta MJ, Vanbever R. Optimization of the aerosolization properties of an inhalation dry powder based on selection of excipients. Eur J Pharm Biopharm 2008; 70(3): 83944.

[37] Islam N, Gladki E. Dry powder inhalers (DPIs)--a review of device reliability and innovation. Int $\mathrm{J}$ Pharm 2008; 360(1-2): 1-11.

[38] Newman SP. Dry powder inhalers for optimal drug delivery. Expert Opin Biol Ther 2004; 4(1): 23-33.

[39] Ashurst II, Malton A, Prime D, Sumby B. Latest advances in the development of dry powder inhalers. Pharm Sci Technolo Today 2000; 3(7): 246-256.

[40] Ganderton D. Targeted delivery of inhaled drugs: current challenges and future goals. J Aerosol Med 1999; 12(1): S3-8.

[41] O'Connor BJ. The ideal inhaler: design and characteristics to improve outcomes. Respir Med 2004; 98(A): S10-6.

[42] Geller DE1, Weers J, Heuerding S. Development of an inhaled dry-powder formulation of tobramycin using PulmoSphere ${ }^{\mathrm{TM}}$ technology. J Aerosol Med Pulm Drug Deliv 2011; 24(4): 175-82.

[43] Döring G, Flume P, Heijerman H, Elborn JS; Consensus Study Group. Treatment of lung infection in patients with cystic fibrosis: current and future strategies. J Cyst Fibros. 2012; 11(6): 461-79.

[44] NCT01270347. Trial of Aeroquin Versus Tobramycin Inhalation Solution (TIS) in Cystic Fibrosis (CF) Patients. Available at https://clinicaltrials.gov/ct2/show/ [accessed September 22, 2015]. 
[45] Ehsan Z, Clancy J. T100: nebulized-concentrated tobramycin formulation for treatment of Pseudomonas aeruginosa infection in cystic fibrosis patients. Expert Opin. Orphan Drugs 2015; 3(8): 933-43.

[46] Anastasi JK, Thomas F. Dealing with HIV-related pulmonary infections. Nursing. 1994; 24(11): 60-5.

[47] BAYQ3939. Ciprofloxacin PulmoSphere. Availabale at http://clinicaltrialsfeeds.org/clinicaltrials/results/term=Ciprofloxacin+PulmoSphere,+BA YQ3939 [accessed August 25, 2013].

[48] NCT00391014. Nebulized Liposomal Amphotericin B Ambisome for Prophylaxis of Invasive Pulmonary Aspergillosis. Available at https://clinicaltrials.gov/ct2/show/NCT00391014 [accessed August 20, 2015].

[49] Chang AB, Chang CC, O'Grady K, Torzillo PJ. Lower respiratory tract infections. Pediatr Clin North Am 2009; 56(6): 1303-21.

[50] NICE. Respiratory tract infections - antibiotic prescribing. Prescribing of antibiotics for selflimiting respiratory tract infections in adults and children in primary care. Available from: www.nice.org.uk/guidance/cg69/resources/cg69respiratory-tract-infections-full-guideline3 [accessed July 2015]

[51] Pison U, Welte T, Giersig M, Groneberg DA. Nanomedicine for respiratory diseases. Eur J Pharmacol 2006; 533(1): 341-50.

[52] Murphy TF. The many faces of Pseudomonas aeruginosa in chronic obstructive pulmonary disease. Clin Infect Dis 2008 Dec 15;47(12):1534-6.

[53] Salouti M, Ahangari A. Nanoparticle based Drug Delivery Systems for Treatment of Infectious Diseases. In: Sezer AD. editor. Application of Nanotechnology in Drug Delivery, InTech 2014; pp. 155-92.

[54] Mutlu GM, Wunderink RG. Severe pseudomonal infections. Curr Opin Crit Care 2006; 12(5): 458-63.

[55] Garau J, Gomez L. Pseudomonas aeruginosa pneumonia. Curr Opin Infect Dis 2003; 16(2): 13543.
[56] Lyczak JB, Cannon CL, Pier GB. Lung infections associated with cystic fibrosis. Clin Microbiol Rev 2002; 15(2): 194-222.

[57] Thomassen MJ, Demko CA, Doershuk CF. Cystic fibrosis: a review of pulmonary infections and interventions. Pediatr Pulmonol 1987; 3(5): 334-51.

[58] Cohen TS, Prince A. Cystic fibrosis: a mucosal immunodeficiency syndrome. Nat Med 2012; 18(4): 509-19.

[59] Gibson RL, Burns JL, Ramsey BW. Pathophysiology and management of pulmonary infections in cystic fibrosis. Am J Respir Crit Care Med 2003; 168(8): 918-51.

[60] Pier GB. Pulmonary disease associated with Pseudomonas aeruginosa in cystic fibrosis: current status of the host-bacterium interaction. J Infect Dis $1985 ; 151(4): 575-80$.

[61] Eller J, Ede A, Schaberg T, Niederman MS, Mauch $\mathrm{H}$, Lode $\mathrm{H}$. Infective exacerbations of chronic bronchitis: relation between bacteriologic etiology and lung function. Chest. 1998; 113(6): 1542-8.

[62] Siddiqi A, Sethi S. Optimizing antibiotic selection in treating COPD exacerbations. Int J Chron Obstruct Pulmon Dis 2008; 3(1): 31-44.

[63] Martínez-Solano L, Macia MD, Fajardo A, Oliver A, Martinez JL. Chronic Pseudomonas aeruginosa infection in chronic obstructive pulmonary disease. Clin Infect Dis 2008; 47(12): 1526-33.

[64] Fujitani S, Sun HY, Yu VL, Weingarten JA. Pneumonia due to Pseudomonas aeruginosa: part I: epidemiology, clinical diagnosis, and source. Chest. 201; 139(4): 909-19.

[65] Chiang CH. Levofloxacin for the Treatment of Respiratory Tract Infections Based on Treatment Guidelines. Review article available at www.infectweb.com/only/artsrv2006_5.pdf [accessed on August 2015]

[66] Ernst JD. Macrophage receptors for Mycobacterium tuberculosis. Infect Immun 1998; 66(4): 1277-81.

[67] Krutzik SR, Modlin RL. The role of Toll-like receptors in combating mycobacteria. Semin 
Immunol 2004; 16: 35-41.

[68] Stafford JL, Neumann NF, Belosevic M. Macrophage-mediated innate host defense against protozoan parasites. Crit Rev Microbiol 2002; 28(3): 187-248.

[69] Labiris NR, Dolovich MB. Pulmonary drug delivery. Part I: physiological factors affecting therapeutic effectiveness of aerosolized medications. Br J Clin Pharmacol 2003; 56(6): 588-99.

[70] Rajaram MV, Brooks MN, Morris JD, Torrelles JB, Azad AK, Schlesinger LS. Mycobacterium tuberculosis activates human macrophage peroxisome proliferator-activated receptor gamma linking mannose receptor recognition to regulation of immune responses. J Immunol 2010; 185(2): 92942

[71] Davies PD. The world-wide increase in tuberculosis: how demographic changes, HIV infection and increasing numbers in poverty are increasing tuberculosis. Ann Med 2003; 35(4): 235-43.

[72] WHO. WHO Global Tuberculosis Report 2013 2013. Available at http://www.who.int/tb/publications/factsheet_global. pdf [accessed August 13, 2014].

[73] WHO. Multidrug-resistant TB (MDR-TB): 2013 Update 2013. Available at http://www.who.int/tb/challenges/mdr/mdr_tb_factsh eet.pdf?ua=1 [accessed August 12, 2014].

[74] Van Crevel R1, Ottenhoff TH, Van der Meer JW. Innate immunity to Mycobacterium tuberculosis. Clin Microbiol Rev 2002; 15(2): 294-309.

[75] Limper AH, Knox KS, Sarosi GA, Ampel NM, Bennett JE, Catanzaro A, et al. An official American Thoracic Society statement: Treatment of fungal infections in adult pulmonary and critical care patients. Am J Respir Crit Care Med 2011; 183(1): 96-128.

[76] Tortorano AM, Peman J, Bernhardt H, Klingspor L, Kibbler CC, Faure O, et al. Epidemiology of candidaemia in Europe: results of 28-month European Confederation of Medical Mycology (ECMM) hospital-based surveillance study. Eur J Clin Microbiol Infect Dis 2004; 23(4): 317-22. fatality rate: systematic review of the literature. Clin Infect Dis 2001; 32(3): 358-66.

[78] Wheat LJ, Freifeld AG, Kleiman MB, Baddley JW, McKinsey DS, Loyd JE, et al. Clinical practice guidelines for the management of patients with histoplasmosis: 2007 update by the Infectious Diseases Society of America. Clin Infect Dis 2007; 45(7): 807-25.

[79] Smith JA, Kauffman CA. Pulmonary fungal infections. Respirology 2012; 17(6): 913-26.

[80] Porollo A, Meller J, Joshi Y, Jaiswal V, Smulian AG, Cushion MT. Analysis of current antifungal agents and their targets within the Pneumocystis carinii genome. Curr Drug Targets 2012; 13(12): 1575-85.

[81] Sharma A, Kumar Arya D, Dua M, Chhatwal GS, Johri AK. Nano-technology for targeted drug delivery to combat antibiotic resistance. Expert Opin Drug Deliv 2012; 9(11): 1325-32.

[82] Beyth N, Houri-Haddad Y, Domb A, Khan W, Hazan R. Alternative antimicrobial approach: nanoantimicrobial materials. Evid Based Complement Alternat Med 2015; 2015: 246012.

[83] Stewart PS, Costerton JW. Antibiotic resistance of bacteria in biofilms. Lancet 2001; 358(9276): 135-8.

[84] Costerton JW, Stewart PS, Greenberg EP. Bacterial biofilms: a common cause of persistent infections. Science 1999; 284(5418): 1318-22.

[85] Solano C, Echeverz M, Lasa I. Biofilm dispersion and quorum sensing. Curr Opin Microbiol 2014; 18: 96-104.

[86] World Health Organization. WHO's first global report on antibiotic resistance reveals serious, worldwide threat to public health. In Antimicrobial resistance-global surveillance report. Virtual Press Conference 2014. Available at http://www.who.int/mediacentre/multimedia/antimic robial-resistance-briefing/en/. [accessed 2015 September]

[87] Smith JP. Nanoparticle delivery of anti-tuberculosis chemotherapy as a potential mediator against drugresistant tuberculosis. Yale J Biol Med 2011; 84(4): $361-9$.

[88] Shafer WM, Folster JP. Towards an understanding of 
chromosomally mediated penicillin resistance in Neisseria gonorrhoeae: evidence for a porin-efflux pump collaboration. J Bacteriol 2006; 188(7): 22979.

[89] Speer BS, Shoemaker NB, Salyers AA. Bacterial resistance to tetracycline: mechanisms, transfer, and clinical significance. Clin Microbiol Rev 1992; 5(4): 387-99.

[90] Kong KF, Schneper L, Mathee K. Beta-lactam antibiotics: from antibiosis to resistance and bacteriology. APMIS 2010; 118(1): 1-36.

[91] Jacoby GA. Mechanisms of resistance to quinolones. Clin Infect Dis 2005; 41(2): S120-6.

[92] Springer B, Kidan YG, Prammananan T, Ellrott K, Böttger EC, Sander P. Mechanisms of streptomycin resistance: selection of mutations in the 16S rRNA gene conferring resistance. Antimicrob Agents Chemother 2001; 45(10): 2877-84.

[93] Wei CJ, Lei B, Musser JM, Tu SC. Isoniazid activation defects in recombinant Mycobacterium tuberculosis catalase-peroxidase (KatG) mutants evident in InhA inhibitor production. Antimicrob Agents Chemother 2003; 47(2): 670-5.

[94] Ahmad S, Mokaddas E. Recent advances in the diagnosis and treatment of multidrug-resistant tuberculosis. Respir Med 2009; 103(12): 1777-90.

[95] Fernández L, Hancock RE. Adaptive and mutational resistance: role of porins and efflux pumps in drug resistance. Clin Microbiol Rev 2012; 25(4): 661-81.

[96] Kater A, Henke MO, Rubin BK. The role of DNA and actin polymers on the polymer structure and rheology of cystic fibrosis sputum and depolymerization by gelsolin or thymosin beta 4 . Ann N Y Acad Sci 2007; 1112: 140-53.

O'Donnell AE. Bronchiectasis. Chest. 2008; 134(4): 815-23.

[98] Hadinoto K, Cheow WS. Nano-antibiotics in chronic lung infection therapy against Pseudomonas aeruginosa. Colloids Surf B Biointerfaces 2014; 116: $772-85$

[99] Hunt BE, Weber A, Berger A, Ramsey B, Smith AL. Macromolecular mechanisms of sputum inhibition of tobramycin activity. Antimicrob Agents Chemother
1995; 39(1): 34-9.

[100] Ibrahim BM, Tsifansky MD, Yang Y, Yeo Y. Challenges and advances in the development of inhalable drug formulations for cystic fibrosis lung disease. Expert Opin Drug Deliv 2011; 8(4): 451-66.

[101] Danahay H, Jackson AD. Epithelial mucushypersecretion and respiratory disease. Curr Drug Targets Inflamm Allergy 2005; 4(6): 651-64.

[102] Worlitzsch D, Tarran R, Ulrich M, Schwab U, Cekici A, Meyer KC, et al. Effects of reduced mucus oxygen concentration in airway Pseudomonas infections of cystic fibrosis patients. J Clin Invest 2002; 109(3): 317-25.

[103] Hassett DJ, Sutton MD, Schurr MJ, Herr AB, Caldwell CC, Matu JO. Pseudomonas aeruginosa hypoxic or anaerobic biofilm infections within cystic fibrosis airways. Trends Microbiol 2009; 17(3): 1308 .

[104] Pritt B, O'Brien L, Winn W. Mucoid Pseudomonas in cystic fibrosis. Am J Clin Pathol 2007; 128(1): 324.

[105] Landry RM, An D, Hupp JT, Singh PK, Parsek MR. Mucin-Pseudomonas aeruginosa interactions promote biofilm formation and antibiotic resistance. Mol Microbiol 2006; 59(1): 142-51.

[106] Marianecci C, Di Marzio L, Rinaldi F, Carafa M, Alhaique F. Pulmonary delivery: innovative approaches and perspectives. J Biomater Nanobiotech 2011; 2(05): 567.

[107] Pandey S, Choudhary A, Patel B, Mahalaxmi R, Devmurari V, Jivani NP. Pulmonary Delivery as a Route for Insulin. Int J PharmTech Res 2009; 1(4): $1190-7$

[108] Madhav NVS, Dwivedi G. Pulmonary drug delivery: a review | PharmaTutor. Available at http://www.pharmatutor.org/articles/pulmonarydrug-delivery-a-review?page $=0,3$ [accessed August $9,2013]$

[109] Lai SK, Wang YY, Hanes J. Mucus-penetrating nanoparticles for drug and gene delivery to mucosal tissues. Adv Drug Deliv Rev 2009; 61(2): 158-71.

[110] Ferreira AJ, Cemlyn-Jones J, Robalo Cordeiro C. Nanoparticles, nanotechnology and pulmonary nanotoxicology. Rev Port Pneumol 2013; 19(1): 28- 
37.

[111] Andujar P, Lanone S, Brochard P, Boczkowski J. Respiratory effects of manufactured nanoparticles. Rev Mal Respir 2011; 28(8): e66-75.

[112] Li JJ, Muralikrishnan S, Ng CT, Yung LY, Bay BH. Nanoparticle-induced pulmonary toxicity. Exp Biol Med (Maywood) 2010; 235(9): 1025-33.

[113] Beck-Broichsitter M, Ruppert C, Schmehl T, Guenther A, Betz T, Bakowsky U, et al. Biophysical investigation of pulmonary surfactant surface properties upon contact with polymeric nanoparticles in vitro. Nanomedicine 2011; 7(3): 341-50.

[114] Mansour HM, Rhee YS, Wu X. Nanomedicine in pulmonary delivery. Int $\mathbf{J}$ Nanomedicine 2009; 4: 299-319.

[115] Puri A, Loomis K, Smith B, Lee JH, Yavlovich A, Heldman E, et al. Lipid-based nanoparticles as pharmaceutical drug carriers: from concepts to clinic. Crit Rev Ther Drug Carrier Syst 2009; 26(6): 523-80.

[116] Drulis-Kawa Z, Dorotkiewicz-Jach A. Liposomes as delivery systems for antibiotics. Int J Pharm 2010; 387(1-2): 187-98.

[117] Pinto-Alphandary H1, Andremont A, Couvreur P. Targeted delivery of antibiotics using liposomes and nanoparticles: research and applications. Int $\mathbf{J}$ Antimicrob Agents 2000; 13(3): 155-68.

[118] Omri A, Suntres ZE, Shek PN. Enhanced activity of liposomal polymyxin B against Pseudomonas aeruginosa in a rat model of lung infection. Biochem Pharmacol 2002; 64(9): 1407-13.

[119] SP Vyas, RK Khar. Targeted \& controlled drug delivery. CBC Publisher \& distributors 2004 , New Delhi, pp. 459-463.

[120] Bridges PA, Taylor KM. Nebulisers for the generation of liposomal aerosols. Int J Pharm 1998; 173(1): 117-25.

[121] Farr SJ, Kellaway IW, Parry-Jones DR, Woolfrey SG. $99 \mathrm{~m}-$ Technetium as a marker of liposomal deposition and clearance in the human lung. Int $\mathbf{J}$ Pharm 1985; 26(3): 303-16.

[122] Deshpande D, Blanchard J, Srinivasan S, Fairbanks
D, Fujimoto J, Sawa T, et al. Aerosolization of lipoplexes using AERx Pulmonary Delivery System. AAPS PharmSci 2002; 4(3): E13.

[123] McLachlan G, Baker A, Tennant P, Gordon C, Vrettou C, Renwick L, et al. Optimizing aerosol gene delivery and expression in the ovine lung. Mol Ther 2007; 15(2): 348-54.

[124] Jain NK, Mishra V, Mehra NK. Targeted drug delivery to macrophages. Expert Opin Drug Deliv 2013; 10(3): 353-67.

[125] Svenson, S.; Prud'homme, R. K., Eds. Multifunctional Nanoparticles for Drug Delivery Applications; Nanostructure Science and Technology Series; Springer: New York, Dordrecht, Heidelberg, London, 2012

[126] Bridges PA, Taylor KM. An investigation of some of the factors influencing the jet nebulisation of liposomes. Int J Pharm 2000; 204(1-2): 69-79.

[127] Chattopadhyay S, Ehrman SH, Bellare J, Venkataraman C. Morphology and bilayer integrity of small liposomes during aerosol generation by airjet nebulisation. J Nanoparticle Res 2012; 14(4): 1-5.

[128] Kleemann E, Schmehl T, Gessler T, Bakowsky U, Kissel T, Seeger W. Iloprost-containing liposomes for aerosol application in pulmonary arterial hypertension: formulation aspects and stability. Pharm Res 2007; 24(2): 277-87.

[129] Radhakrishnan R, Mihalko PJ, Abra RM, inventor; Liposome Technology Inc., assignee. Method and apparatus for administering dehydrated liposomes by inhalation. United States patent US 4895719 A. 1990 Jan.

[130] Taylor KM, Newton JM. Liposomes for controlled delivery of drugs to the lung. Thorax 1992; 47(4): 257-9.

[131] Taylor E, Webster TJ. Reducing infections through nanotechnology and nanoparticles. Int $\mathbf{J}$ Nanomedicine 2011; 6: 1463-73.

[132] Salih SB, Kharal M, Qahtani M, Dahneem L, Nohair S. Acute interstitial nephritis induced by intermittent use of rifampicin in patient with brucellosis. Saudi J Kidney Dis Transpl 2008; 19(3): 450-2.

[133] Prakash J, Kumar NS, Saxena RK, Verma U. Acute 
renal failure complicating rifampicin therapy. $\mathbf{J}$ Assoc Physicians India 2001; 49: 877-80.

[134] Covic A, Goldsmith DJ, Segall L, Stoicescu C, Lungu S, Volovat C, et al. Rifampicin-induced acute renal failure: a series of 60 patients. Nephrol Dial Transplant 1998; 13(4): 924-9.

[135] Kunimoto D, Warman A, Beckon A, Doering D, Melenka L. Severe hepatotoxicity associated with rifampin-pyrazinamide preventative therapy requiring transplantation in an individual at low risk for hepatotoxicity. Clin Infect Dis 2003; 36(12): e158-61.

[136] Min HK, Kim EO, Lee SJ, Chang YK, Suh KS, Yang CW, et al. Rifampin-associated tubulointersititial nephritis and Fanconi syndrome presenting as hypokalemic paralysis. BMC Nephrol 2013; $14: 13$.

[137] Deol P, Khuller GK, Joshi K. Therapeutic efficacies of isoniazid and rifampin encapsulated in lungspecific stealth liposomes against Mycobacterium tuberculosis infection induced in mice. Antimicrob Agents Chemother 1997; 41(6): 1211-4.

[138] Changsan N, Nilkaeo A, Pungrassami P, Srichana T. Monitoring safety of liposomes containing rifampicin on respiratory cell lines and in vitro efficacy against Mycobacterium bovis in alveolar macrophages. J Drug Target 2009; 17(10): 751-62.

[139] Manca ML, Sinico C, Maccioni AM, Diez O, Fadda AM, Manconi M. Composition influence on pulmonary delivery of rifampicin liposomes. Pharmaceutics 2012; 4(4): 590-606.

[140] Traini D, Young PM. Delivery of antibiotics to the respiratory tract: an update. Expert Opin Drug Deliv 2009; 6(9): 897-905.

[141] Lasic DD, Papahadjopoulos D, editors. Medical applications of liposomes. Elsevier; 1998 Jul.

[142] Donald PR, Sirgel FA, Venter A, Smit E, Parkin DP, Van de Wal BW, et al. The early bactericidal activity of a low-clearance liposomal amikacin in pulmonary tuberculosis. J Antimicrob Chemother 2001; 48(6): 877-80.

[143] Khuller GK, Kapur M, Sharma S. Liposome technology for drug delivery against mycobacterial infections. Curr Pharm Des 2004; 10(26): 3263-74.
[144] Schiffelers R, Storm G, Bakker-Woudenberg I. Liposome-encapsulated aminoglycosides in preclinical and clinical studies. J Antimicrob Chemother 2001; 48(3): 333-44.

[145] Beaulac C, Clément-Major S, Hawari J, Lagacé J. Eradication of mucoid Pseudomonas aeruginosa with fluid liposome- encapsulated tobramycin in an animal model of chronic pulmonary infection. Antimicrob Agents Chemother 1996; 40(3): 665-9.

[146] Pinheiro M, Lúcio M, Lima JL, Reis S. Liposomes as drug delivery systems for the treatment of TB. Nanomedicine (Lond) 2011; 6(8): 1413-28.

[147] Pandey R, Sharma S, Khuller GK. Nebulization of liposome encapsulated antitubercular drugs in guinea pigs. Int J Antimicrob Agents 2004; 24(1): 93-4.

[148] Deol P, Khuller GK. Lung specific stealth liposomes: stability, biodistribution and toxicity of liposomal antitubercular drugs in mice. Biochim Biophys Acta 1997; 1334(2-3): 161-72.

[149] Vyas SP, Kannan ME, Jain S, Mishra V, Singh P. Design of liposomal aerosols for improved delivery of rifampicin to alveolar macrophages. Int $\mathrm{J}$ Pharm 2004; 269(1): 37-49.

[150] Wijagkanalan W, Kawakami S, Takenaga M, Igarashi R, Yamashita F, Hashida M. Efficient targeting to alveolar macrophages by intratracheal administration of mannosylated liposomes in rats. $\mathrm{J}$ Control Release 2008; 125(2): 121-30.

[151] Chono S, Kaneko K, Yamamoto E, Togami K, Morimoto K. Effect of surface-mannose modification on aerosolized liposomal delivery to alveolar macrophages. Drug Dev Ind Pharm 2010; 36(1): 102-7.

[152] Wong JP, Yang H, Blasetti KL, Schnell G, Conley J, Schofield LN. Liposome delivery of ciprofloxacin against intracellular Francisella tularensis infection. J Control Release 2003; 92(3): 265-73.

[153] Zhang L, Pornpattananangku D, Hu CM, Huang CM. Development of nanoparticles for antimicrobial drug delivery. Curr Med Chem 2010; 17(6): 585-94.

[154] Chougule M, Padhi B, Misra A. Development of spray dried liposomal dry powder inhaler of Dapsone. AAPS PharmSciTech 2008; 9(1): 47-53.

[155] Oh YK, Nix DE, Straubinger RM. Formulation and 
efficacy of liposome-encapsulated antibiotics for therapy of intracellular Mycobacterium avium infection. Antimicrob Agents Chemother 1995; 39(9): 2104-11.

[156] Smola M, Vandamme T, Sokolowski A. Nanocarriers as pulmonary drug delivery systems to treat and to diagnose respiratory and non respiratory diseases.Int J Nanomedicine 2008; 3(1): 1-19.

[157] Rytting E, Nguyen J, Wang $\mathrm{X}$, Kissel T. Biodegradable polymeric nanocarriers for pulmonary drug delivery. Expert Opin Drug Deliv 2008; 5(6): 629-39.

[158] Imbuluzqueta E, Gamazo C, Ariza J, Blanco-Prieto MJ. Drug delivery systems for potential treatment of intracellular bacterial infections. Front Biosci (Landmark Ed) 2010; 15: 397-417.

[159] Vilos C, Velasquez LA. Therapeutic strategies based on polymeric microparticles. J Biomed Biotechnol 2012; 2012: 672760 .

[160] Mc Callion ON, Taylor KM, Thomas M, Taylor AJ. Nebulisation of monodisperse latex sphere suspensions in air jet and ultrasonic nebulisers. Int. J Pharm 1996; 133(1): 203-14.

[161] Dailey LA, Schmehl T, Gessler T, Wittmar M, Grimminger F, Seeger W, et al. Nebulization of biodegradable nanoparticles: impact of nebulizer technology and nanoparticle characteristics on aerosol features. J Control Release 2003; 86(1): 13144.

[162] Sung JC, Pulliam BL, Edwards DA. Nanoparticles for drug delivery to the lungs. Trends Biotechnol 2007; 25(12): 563-70.

[163] Skidan IN, Gel'perina SE, Severin SE, Guliaev AE. Enhanced activity of rifampicin loaded with polybutyl cyanoacrylate nanoparticles in relation to intracellularly localized bacteria. Antibiot Khimioter 2003; 48(1): 23-6.

[164] Ungaro F, D'Angelo I, Coletta C, D'Emmanuele di Villa Bianca R, Sorrentino R, Perfetto B,et al. Dry powders based on PLGA nanoparticles for pulmonary delivery of antibiotics: modulation of encapsulation efficiency, release rate and lung deposition pattern by hydrophilic polymers. J Control Release 2012; 157(1): 149-59.

[165] Arnold MM, Gorman EM, Schieber LJ, Munson EJ,
Berkland C. NanoCipro encapsulation in monodisperse large porous PLGA microparticles. J Control Release 2007; 121(1-2): 100-9.

[166] Tsifansky MD, Yeo Y, Evgenov OV, Bellas E, Benjamin J, Kohane DS. Microparticles for inhalational delivery of antipseudomonal antibiotics. AAPS J 2008; 10(2): 254-60.

[167] Zhao L1, Zhu B, Jia Y, Hou W, Su C. Preparation of biocompatible carboxymethyl chitosan nanoparticles for delivery of antibiotic drug. Biomed Res Int 2013; 2013: 236469.

[168] Pandey R, Khuller GK. Solid lipid particle-based inhalable sustained drug delivery system against experimental tuberculosis. Tuberculosis (Edinb) 2005; 85(4): 227-34.

[169] Kabanov AV, Batrakova EV, Alakhov VY. Pluronic ${ }^{\circledR}$ block copolymers as novel polymer therapeutics for drug and gene delivery. J Control Release 2002; 82(2-3): 189-212.

[170] La SB, Okano T, Kataoka K. Preparation and characterization of the micelle-forming polymeric drug indomethacin-incorporated poly(ethylene oxide)-poly(beta-benzyl L-aspartate) block copolymer micelles. J Pharm Sci 1996; 85(1): 85-90.

[171] Sahib MN, Abdulameer SA, Darwis Y, Peh KK, Tan YT. Solubilization of beclomethasone dipropionate in sterically stabilized phospholipid nanomicelles (SSMs): physicochemical and in vitro evaluations. Drug Des Devel Ther 2012; 6: 29-42.

[172] Gilani K, Moazeni E, Ramezanli T, Amini M, Fazeli MR, Jamalifar H. Development of respirable nanomicelle carriers for delivery of amphotericin B by jet nebulization. J Pharm Sci 2011; 100(1): 252-9.

[173] Vadakkan MV, Annapoorna K, Sivakumar KC, Mundayoor S, Kumar GS. Dry powder cationic lipopolymeric nanomicelle inhalation for targeted delivery of antitubercular drug to alveolar macrophage. Int J Nanomedicine 2013; 8: 2871-85.

[174] Tsapis N, Bennett D, Jackson B, Weitz DA, Edwards DA. Trojan particles: large porous carriers of nanoparticles for drug delivery. Proc Natl Acad Sci U S A 2002; 99(19): 12001-5.

[175] Edwards DA, Ben-Jebria A, Langer R. Recent advances in pulmonary drug delivery using large, 
porous inhaled particles. J Appl Physiol (1985) 1998; 85(2): 379-85.

[176] Garcia-Contreras L, Fiegel J, Telko MJ, Elbert K, Hawi A, Thomas $\mathrm{M}$, et al. Inhaled large porous particles of capreomycin for treatment of tuberculosis in a guinea pig model. Antimicrob Agents Chemother 2007; 51(8): 2830-6.

[177] Suarez S, O'Hara P, Kazantseva M, Newcomer CE, Hopfer R, McMurray DN, et al. Respirable PLGA microspheres containing rifampicin for the treatment of tuberculosis: screening in an infectious disease model. Pharm Res 2001; 18(9): 1315-9.

[178] Edwards DA, Hanes J, Caponetti G, Hrkach J, BenJebria A, Eskew ML, et al. Large porous particles for pulmonary drug delivery. Science. 1997; 276(5320): 1868-71.

[179] Lester MK, Flume PA, Gray SL, Anderson D, Bowman CM. Nebulizer use and maintenance by cystic fibrosis patients: a survey study. Respir Care 2004; 49(12): 1504-8.

[180] Stass H, Nagelschmitz J, Willmann S, Delesen H, Gupta A, Baumann S. Inhalation of a dry powder ciprofloxacin formulation in healthy subjects: a phase I study. Clin Drug Investig 2013; 33(6): 41927.

[181] NCT00961038. Study to Evaluate the Safety and Pharmacokinetics of Inhaled Ciprofloxacin in Patients With Moderate to Severe Chronic Obstructive Pulmonary Disease (COPD). Available at https://clinicaltrials.gov/ct2/show/NCT00961038 [accessed September 22, 2015].

[182] NCT00645788. Study to Evaluate the Safety and Efficacy of Ciprofloxacin (Inhaled) in Patients With Cystic Fibrosis. Available at https://clinicaltrials.gov/ct2/show/NCT00645788 [accessed September 22, 2015].

[183] Mugabe C, Azghani AO, Omri A. Liposomemediated gentamicin delivery: development and activity against resistant strains of Pseudomonas aeruginosa isolated from cystic fibrosis patients. J Antimicrob Chemother 2005; 55(2): 269-71.

[184] Forier K, Raemdonck K, De Smedt SC, Demeester J, Coenye T, Braeckmans K. Lipid and polymer nanoparticles for drug delivery to bacterial biofilms. J Control Release 2014; 190: 607-23.
[185] Turos E, Reddy GS, Greenhalgh K, Ramaraju P, Abeylath SC, Jang S, et al. Penicillin-bound polyacrylate nanoparticles: restoring the activity of beta-lactam antibiotics against MRSA. Bioorg Med Chem Lett 2007; 17(12): 3468-72.

[186] Abeylath SC, Turos E. Drug delivery approaches to overcome bacterial resistance to beta-lactam antibiotics. Expert Opin Drug Deliv 2008; 5(9): 93149.

[187] Alipour M, Suntres ZE, Halwani M, Azghani AO, Omri A. Activity and interactions of liposomal antibiotics in presence of polyanions and sputum of patients with cystic fibrosis. PLoS One 2009; 4(5): e5724.

[188] Ramphal R, Lhermitte M, Filliat M, Roussel P. The binding of anti-pseudomonal antibiotics to macromolecules from cystic fibrosis sputum. J Antimicrob Chemother 1988; 22(4): 483-90.

[189] Halwani M, Blomme S, Suntres ZE, Alipour M, Azghani AO, Kumar A, et al. Liposomal bismuthethanedithiol formulation enhances antimicrobial activity of tobramycin. Int J Pharm 2008; 358(1-2): $278-84$.

[190] Halwani M, Yebio B, Suntres ZE, Alipour M, Azghani AO, Omri A. Co-encapsulation of gallium with gentamicin in liposomes enhances antimicrobial activity of gentamicin against Pseudomonas aeruginosa. J Antimicrob Chemother 2008; 62(6): $1291-7$.

[191] Alipour M, Dorval C, Suntres ZE, Omri A. Bismuthethanedithiol incorporated in a liposome-loaded tobramycin formulation modulates the alginate levels in mucoid Pseudomonas aeruginosa. J Pharm Pharmacol 2011; 63(8): 999-1007.

[192] Alipour M, Suntres ZE, Lafrenie RM, Omri A. Attenuation of Pseudomonas aeruginosa virulence factors and biofilms by co-encapsulation of bismuthethanedithiol with tobramycin in liposomes. J Antimicrob Chemother 2010; 65(4): 684-93.

[193] Halwani M, Hebert S, Suntres ZE, Lafrenie RM, Azghani AO, Omri A. Bismuth-thiol incorporation enhances biological activities of liposomal tobramycin against bacterial biofilm and quorum sensing molecules production by Pseudomonas aeruginosa. Int J Pharm 2009; 373(1-2): 141-6. 
[194] Alhariri M, Omri A. Efficacy of liposomal bismuthethanedithiol-loaded tobramycin after intratracheal administration in rats with pulmonary Pseudomonas aeruginosa infection. Antimicrob Agents Chemother 2013; 57(1): 569-78.

[195] Pedersen SS, Koch C, Høiby N, Rosendal K. An epidemic spread of multiresistant Pseudomonas aeruginosa in a cystic fibrosis centre. J Antimicrob Chemother 1986; 17(4): 505-16.

[196] Hutabarat RM, Unadkat JD, Kushmerick P, Aitken ML, Slattery JT, Smith AL. Disposition of drugs in cystic fibrosis. III. Acetaminophen. Clin Pharmacol Ther 1991; 50(6): 695-701.

[197] Adi H, Young PM, Chan HK, Salama R, Traini D. Controlled release antibiotics for dry powder lung delivery. Drug Dev Ind Pharm 2010; 36(1): 119-26.

[198] Lam J, Chan R, Lam K, Costerton JW. Production of mucoid microcolonies by Pseudomonas aeruginosa within infected lungs in cystic fibrosis. Infect Immun 1980; 28(2): 546-56.

[199] Omri A, Beaulac C, Bouhajib M, Montplaisir S, Sharkawi M, Lagacé J. Pulmonary retention of free and liposome-encapsulated tobramycin after intratracheal administration in uninfected rats and rats infected with Pseudomonas aeruginosa. Antimicrob. Antimicrob Agents Chemother 1994; 38(5): 1090-5.

[200] Smith BR, LeFrock JL. Bronchial tree penetration of antibiotics. Chest 1983; 83(6): 904-8.

[201] Thomas DA, Myers MA, Wichert B, Schreier H, Gonzalez-Rothi RJ. Acute effects of liposome aerosol inhalation on pulmonary function in healthy human volunteers. Chest 1991; 99(5): 1268-70.

[202] Mathur V, Mudnaik R, Barde L, Roy A, Shivhare U, Bhusari K. Formulation and evaluation of controlled release antibiotic biodegradable implants for post operative site delivery. Acta Pharm 2010; 60(1): 111-7.

[203] Fulzele SV, Satturwar PM, Dorle AK. Novel biopolymers as implant matrix for the delivery of ciprofloxacin: biocompatibility, degradation, and in vitro antibiotic release. J Pharm Sci 2007; 96(1): $132-44$.
[204] Ramchandani M, Robinson D. In vitro and in vivo release of ciprofloxacin from PLGA 50:50 implants. J Control Release 1998; 54(2): 167-75.

[205] Bastari K, Arshath M, Ng ZH, Chia JH, Yow ZX, Sana B, et al. A controlled release of antibiotics from calcium phosphate-coated poly(lactic-co-glycolic acid) particles and their in vitro efficacy against Staphylococcus aureus biofilm. J Mater Sci Mater Med 2014; 25(3): 747-57.

[206] Abdelghany SM, Quinn DJ, Ingram RJ, Gilmore BF, Donnelly RF, Taggart CC, et al. Gentamicin-loaded nanoparticles show improved antimicrobial effects towards Pseudomonas aeruginosa infection. Int $\mathrm{J}$ Nanomedicine 2012; 7: 4053-63.

[207] Cheow WS, Chang MW, Hadinoto K. Antibacterial efficacy of inhalable levofloxacin-loaded polymeric nanoparticles against E. coli biofilm cells: the effect of antibiotic release profile. Pharm Res 2010; 27(8): 1597-609.

[208] Abdollahi S, Lotfipour F. PLGA-and PLA-based polymeric nanoparticles for antimicrobial drug delivery. Biomed Int 2015; 3(1): 1-11.

[209] Yang L, Liu Y, Wu H, Song Z, Høiby N, Molin S, et al. Combating biofilms. FEMS Immunol Med Microbiol 2012; 65(2): 146-57.

[210] Briones E, Colino CI, Lanao JM. Delivery systems to increase the selectivity of antibiotics in phagocytic cells. J Control Release 2008 ;125(3): 210-27.

[211] Hand WL, King-Thompson N, Holman JW. Entry of roxithromycin (RU 965), imipenem, cefotaxime, trimethoprim, and metronidazole into human polymorphonuclear leukocytes. Antimicrob Agents Chemother 1987; 31(10): 1553-7.

[212] Maurin M, Raoult D. Use of aminoglycosides in treatment of infections due to intracellular bacteria. Antimicrob. Antimicrob Agents Chemother 2001; 45(11): 2977-86.

[213] Adams LB, Sinha I, Franzblau SG, Krahenbuhl JL, Mehta RT. Effective treatment of acute and chronic murine tuberculosis with liposome-encapsulated clofazimine. Antimicrob Agents Chemother 1999; 43(7): 1638-43. 
[214] Mehta RT. Liposome encapsulation of clofazimine reduces toxicity in vitro and in vivo and improves therapeutic efficacy in the beige mouse model of disseminated Mycobacterium avium-M. intracellulare complex infection. Antimicrob Agents Chemother 1996; 40(8): 1893-902.

[215] Stoops JK, Arora R, Armitage L, Wanger A, Song L, Blackburn MR, et al. Certain surfactants show promise in the therapy of pulmonary tuberculosis. In Vivo 2010; 24(5): 687-94.

[216] Dzau VJ, Mann MJ, Morishita R, Kaneda Y. Fusigenic viral liposome for gene therapy in cardiovascular diseases. Proc Natl Acad Sci U S A 1996; 93(21): 11421-5.

[217] Cevc G. How membrane chain-melting phasetransition temperature is affected by the lipid chain asymmetry and degree of unsaturation: an effective chain-length model. Biochemistry 1991; 30(29): 7186-93.

[218] Vidal M, Hoekstra D. In vitro fusion of reticulocyte endocytic vesicles with liposomes. J Biol Chem 1995; 270(30): 17823-9.

[219] Nicolosi D, Scalia M, Nicolosi VM, Pignatello R. Encapsulation in fusogenic liposomes broadens the spectrum of action of vancomycin against Gramnegative bacteria. Int J Antimicrob Agents 2010; 35(6): 553-8.

[220] Chong PL, Choate D. Calorimetric studies of the effects of cholesterol on the phase transition of C(18):C(10) phosphatidylcholine. Biophys J 1989; 55(3): 551-6.

[221] Pagès JM, James CE, Winterhalter $M$. The porin and the permeating antibiotic: a selective diffusion barrier in Gram-negative bacteria. Nat Rev Microbiol 2008; 6(12): 893-903.

[222] Hancock RE. Resistance mechanisms in Pseudomonas aeruginosa and other nonfermentative gram-negative bacteria. Clin Infect Dis 1998; 27 (1): S93-9.

[223] Hancock RE, Brinkman FS. Function of pseudomonas porins in uptake and efflux. Annu Rev Microbiol 2002; 56: 17-38.

[224] Vila J, Martí S, Sánchez-Céspedes J. Porins, efflux pumps and multidrug resistance in Acinetobacter baumannii. J Antimicrob Chemother 2007; 59(6): $1210-5$.

[225] Pignatello R, Nicolosi D, Nicolosi VM. Fusogenic liposomes as new carriers to enlarge the spectrum of action of antibiotic drugs against Gram-negative bacteria. In: Mendez-Vilas A, editor. Science against microbial pathogens: communicating current research and technological advances. Formatex Research Center. Spain 2011; pp 52-60.

[226] Beaulac C, Clément-Major S, Hawari J, Lagacé J. Eradication of mucoid Pseudomonas aeruginosa with fluid liposome-encapsulated tobramycin in an animal model of chronic pulmonary infection. Antimicrob Agents Chemother 1996; 40(3): 665-9.

[227] Li X, Yeh YC, Giri K, Mout R, Landis RF, Prakash YS, et al. Control of nanoparticle penetration into biofilms through surface design. Chem Commun (Camb) 2015; 51(2): 282-5.

[228] Messiaen AS, Forier K, Nelis H, Braeckmans K, Coenye T. Transport of Nanoparticles and Tobramycin-loaded Liposomes in Burkholderia cepacia Complex Biofilms. PLoS One 2013; 8(11): e79220.

[229] Suk JS, Lai SK, Wang YY, Ensign LM, Zeitlin PL, Boyle MP, et al. The penetration of fresh undiluted sputum expectorated by cystic fibrosis patients by non-adhesive polymer nanoparticles. Biomaterials 2009; 30(13): 2591-7.

[230] Tang BC, Dawson M, Lai SK, Wang YY, Suk JS, Yang $\mathrm{M}$, et al. Biodegradable polymer nanoparticles that rapidly penetrate the human mucus barrier. Proc Natl Acad Sci U S A 2009; 106(46): 19268-73.

[231] Sosnik A, Carcaboso AM, Glisoni RJ, Moretton MA, Chiappetta DA. New old challenges in tuberculosis: Potentially effective nanotechnologies in drug delivery. Adv Drug Deliv Rev 2010; 62(4-5): 54759.

[232] Sharma R, Saxena D, Dwivedi AK, Misra A. Inhalable microparticles containing drug combinations to target alveolar macrophages for treatment of pulmonary tuberculosis. Pharm Res 2001; 18(10): 1405-10.

[233] Quenelle DC, Winchester GA, Staas JK, Barrow EL, Barrow WW. Treatment of tuberculosis using a 
combination of sustained-release rifampin-loaded microspheres and oral dosing with isoniazid. Antimicrob Agents Chemother 2001; 45(6): 163744.

[234] Kalluru R, Fenaroli F, Westmoreland D, Ulanova L, Maleki A, Roos N, et al. Poly(lactide-co-glycolide)rifampicin nanoparticles efficiently clear Mycobacterium bovis BCG infection in macrophages and remain membrane-bound in phagolysosomes. J Cell Sci 2013; 126(14): 3043-54.

[235] Panyam J, Labhasetwar V. Dynamics of endocytosis and exocytosis of poly(D,L-lactide-co-glycolide) nanoparticles in vascular smooth muscle cells. Pharm Res 2003; 20(2): 212-20.

[236] Makino K, Nakajima T, Shikamura M, Ito F, Ando $\mathrm{S}$, Kochi C, et al. Efficient intracellular delivery of rifampicin to alveolar macrophages using rifampicinloaded PLGA microspheres: effects of molecular weight and composition of PLGA on release of rifampicin. Colloids Surf B Biointerfaces 2004; 36(1): 35-42.

[237] Hirota $K$, Hasegawa $T$, Nakajima $T$, Inagawa $H$, Kohchi C, Soma G, et al. Delivery of rifampicinPLGA microspheres into alveolar macrophages is promising for treatment of tuberculosis. J Control Release 2010; 142(3): 339-46.

[238] Barrow EL, Winchester GA, Staas JK, Quenelle DC, Barrow WW. Use of microsphere technology for targeted delivery of rifampin to Mycobacterium tuberculosis-infected macrophages. Antimicrob Agents Chemother 1998; 42(10): 2682-9.

[239] Anisimova YV, Gelperina SI, Peloquin CA, Heifets LB. Nanoparticles as antituberculosis drugs carriers: effect on activity against Mycobacterium tuberculosis in human monocyte-derived macrophages. J Nanopart. Res 2000; 2(2): 165-71.

[240] Cui Z, Hsu CH, Mumper RJ. Physical characterization and macrophage cell uptake of mannan-coated nanoparticles. Drug Dev Ind Pharm 2003; 29(6): 689-700.

[241] Chaubey P, Mishra B. Mannose-conjugated chitosan nanoparticles loaded with rifampicin for the treatment of visceral leishmaniasis. Carbohydr Polym 2014; 101: 1101-8.
Yoo HS, et al. The potential of mannosylated chitosan microspheres to target macrophage mannose receptors in an adjuvant-delivery system for intranasal immunization. Biomaterials 2008; 29(12): 1931-9.

[243] Kumar PV, Asthana A, Dutta T, Jain NK. Intracellular macrophage uptake of rifampicin loaded mannosylated dendrimers. J Drug Target 2006; 14(8): 546-56.

[244] Nimje N, Agarwal A, Saraogi GK, Lariya N, Rai G, Agrawal $\mathrm{H}$, et al. Mannosylated nanoparticulate carriers of rifabutin for alveolar targeting. J Drug Target 2009; 17(10): 777-87.

[245] Saraogi GK, Sharma B, Joshi B, Gupta P, Gupta UD, Jain NK, et al. Mannosylated gelatin nanoparticles bearing isoniazid for effective management of tuberculosis. J Drug Target 2011; 19(3): 219-27.

[246] NCT00391014. Nebulized Liposomal Amphotericin B Ambisome for Prophylaxis of Invasive Pulmonary Aspergillosis. PETHEMA Foundation 2004. Available http://clinicaltrials.gov/show/NCT00391014 [accessed August 20, 2014].

[247] NCT01615809. Nebulized Amphotericin B Lipid Complex in Invasive Pulmonary Aspergillosis in Paediatric Patients With Acute Leukaemia. Available https://clinicaltrials.gov/ct2/show/NCT01615809 [accessed January 13, 2015].

[248] Allen SD, Sorensen KN, Nejdl MJ, Durrant C, Proffit RT. Prophylactic efficacy of aerosolized liposomal (AmBisome) and non-liposomal (Fungizone) amphotericin B in murine pulmonary aspergillosis. J Antimicrob Chemother 1994; 34(6): 1001-13.

[249] Wilczewska AZ, Niemirowicz K, Markiewicz KH, Car H. Nanoparticles as drug delivery systems. Pharmacol Rep 2012; 64(5): 1020-37.

[250] Bakand S, Hayes A, Dechsakulthorn F. Nanoparticles: a review of particle toxicology following inhalation exposure. Inhal Toxicol 2012; 24(2): 125-35. 
